\title{
A Closed-Loop Supply Chain Problem with Retailing and Recycling Competition
}

\author{
Chuanchao Xu, Bo Li, Yanfei Lan, and Yi Tang \\ College of Management \& Economics, Tianjin University, Tianjin 300072, China \\ Correspondence should be addressed to Yanfei Lan; yanfei-lan@163.com
}

Received 27 March 2014; Accepted 1 July 2014; Published 24 July 2014

Academic Editor: Józef Banaś

Copyright ( 2014 Chuanchao Xu et al. This is an open access article distributed under the Creative Commons Attribution License, which permits unrestricted use, distribution, and reproduction in any medium, provided the original work is properly cited.

\begin{abstract}
We investigate a durable product retailing and recycling problem in a closed-loop supply chain consisting of a single manufacturer and two competitive retailers, in which the manufacturer collects used products via retailers from the consumers and has sufficient channel power over the retailers to act as a Stackelberg leader; the retailers compete in retail products and recycling used products. In order to analyze the impact of retailing and recycling competitions on the profits of the manufacturer and the competitive retailers, two collection models (coordinated collection (Model $C$ ) and decentralized collection (Model $D$ )) are established, respectively. Then, based on game theory, we derive the optimal retail price, the optimal repurchase price, and the optimal profits of the manufacturer and the retailers. The managerial insights demonstrate that more intense retailing competition induces the increase of the manufacturer's profits in both forward and reverse channels and retailers' profits in the forward channel and the decrease of retailers' profits in the reverse channel, while more intense recycling competition induces the decrease of the profits of the manufacturer and retailers in both forward and reverse channels. Finally, numerical examples are given to illustrate the effectiveness of the proposed models.
\end{abstract}

\section{Introduction}

Durable product remanufacturing and processes for sustainable manufacturing play an important role in closedloop supply chain operations. Increasingly, manufacturers are establishing economically viable production and distribution systems that enable remanufacturing of used products in parallel with the manufacturing of new units. Remanufactured products are typically upgraded to the quality standards of new products, so that they can be sold in new product markets.

In current practice, HP, Xerox, and Apple are retail competitive products that utilize retailers for collecting their used products and have created a fully integrated manufacturingremanufacturing strategy around their reusable product lines [1]. For example, HP, on average $70 \%$ of the disposed cartridges are reused in the production of a new one. Each time a cartridge is returned to HP, the retailers are reimbursed a fixed fee per cartridge and the transportation costs [2]. HP collects its used products via retailers, and some remanufacturers or third parties also collect HP's product, which results in competition between HP and remanufacturers/third parties. Thus, many researchers began to investigate the effect of competition on the channel member's decisions in closed-loop supply channel problem.

In current literature, the operations of typical closed-loop supply chain have been widely studied [3-6]. Furthermore, Choi et al. [7] and Yalabik et al. [8] provided an analysis for calculating the optimal acquisition price. Liang et al. [9] proposed an option pricing for used products of different quality. Some literature discussed the competition between channel members which affects their behaviors of decision. Savaskan et al. [1] provided a problem of choosing a suitable channel structure for the collection of end-of-life returns from customers and considered that the retailing competition affects channel members' decision behavior in different collection ways, and Inderfurth [10] extended the research and investigated an optimal pricing decision problem of a fuzzy closed-loop supply chain with retailing competition. Savaskan and van Wassenhove [11] focused on the interaction 
between a manufacturer's reverse channel choice to collect used product and the strategic product pricing decisions under retailing competition in the forward channel. Ofek et al. [12] examined how consumer returns affected competitive sellers' prices, in-store assistance levels, and decisions to offer an online channel in addition to the brick and mortar store.

For the research in reverse channel of closed-loop supply chain, the contracting of collecting the used products affects not only the supply of used products but also the price of the remanufactured product. Hong et al. [13] provided a typical recycling competition of manufacturers who have three reverse collection channel structures to choose: (1) manufacturer and retailer collecting used products have competition at the same time, (2) manufacturer collecting used products have competition with a retailer and a third party, and (3) manufacturer and third party collecting used products have competition at the same time. Choi et al. [14] investigated a closed-loop supply chain (CLSC) which consists of a manufacturer, a third parties collector, and a retailer and examined the performance of different CLSCs under different channel leaderships. Moreover, they illustrated how both the serial and parallel CLSCs can be coordinated by using different kinds of practical contracts. Webster and Mitra [15] and Ferguson and Toktay [16] investigated the joint pricing problem faced by a manufacturer in which a remanufacturable product is derived from heterogeneous consumers and discussed the market and technology drivers of product remanufacturability and identified some phenomena of managerial importance that are typical of a remanufacturing environment. Wu [17] considered a twoperiod closed-loop supply chain problem consisting of two supply chain members, an original equipment manufacturer, and a remanufacturer and investigated the product design decision of the original equipment manufacturer and both chain members' competitive pricing strategies. Tayur and Ganeshan [18] considered that a manufacturer used her foresight about the retailer's and the third party's reaction functions in her decision making. Majumder and Groenevelt [19] examined how third party remanufacturing could induce competitive behavior when the recycling products cannibalize the demand for the original product. Hickey [20] presented that the third parties, such as GENCO distribution system, were also preferred by some consumer goods, under whose experience manufacturers collect the used product. Jung and Hwang [21] provided a typical example of remanufacturing in a reverse channel supply chain with an original equipment manufacturer and a remanufacturer. Chern et al. [22] provided a multiobjective master planning problem for reverse supply chains by considering product structures.

However, among all the literature associated with the closed-loop supply chain problems under competition, most of them have considered the retailing or recycling competition problems respectively, but few of them consider the impact on the closed loop supply chain members involved in retailing and recycling competitions together. Actually, retailing and recycling competitions often exist together in closed-loop supply chain. For example, HP's cartridges, Apple's cellphone, the Xerox's office equipment, and so forth have both retailing and recycling competitions [2]. Based on observations from current practice and the extant literature, we study a competition of retailing and recycling problem in a closed-loop supply chain, in which a manufacturer collects used products via retailers from the consumers and has sufficient channel power over the retailers to act as a Stackelberg leader; the retailers compete in a Bertrand pricing game in the channels of both forward and reverse. In order to analyze the impact of retailing and recycling competitions on the profits of the manufacturer and the competitive retailers, two collection models (coordinated collection (model $C$ ) and decentralized collection (model $D)$ ) are established, respectively. Then we derive the optimal retail price, the optimal repurchase price, and the optimal profits of the manufacturer and the retailers. Finally, numerical examples are given to illustrate the effectiveness of the proposed models.

More specifically, we address the following questions.

(1) How do the competitive factors of retailing and recycling affect the decision of the manufacturer and each retailer (i.e., retail price, repurchase price, wholesale price, and buy-back payment)?

(2) How do the retailing and recycling competitions affect the profits of the channel members?

The rest of the paper is organized as follows. Section 3 describes the assumptions and notations of the modeling framework. The formulations and analysis are presented in Section 4. Section 5 provides the conclusion of the results and possible directions for future research.

\section{Modeling Assumptions and Notations}

This paper investigates a durable product retailing and recycling problem in a closed-loop supply chain consisting of a single manufacturer and two competitive retailers; two collection ways (coordinated collection and decentralized collection) are introduced (see Figure 1).

According to the consumption nature of durable product, assume that the variation of retail price has little effect on the size of retailing market; that is, the demand of market sizes for customers has little sensitivity to retail price, and the variation of repurchase price has little effect on the size of recycling market. Consistent with the extant literature [11], we assume that the manufacturer has sufficient channel power over the retailers to act as a Stackelberg leader, and the retailers compete in a Bertrand pricing game. In order to get more product sale opportunities, the retailers should collect used products for the manufacturer. More specifically, we consider a manufacturer who has incorporated remanufacturing of used products into his/her original product system, so that it can manufacture a new product directly from raw materials or remanufacture part or whole of a returned unit into a new product, and there is no distinction between a remanufactured and a manufactured product. The real archetypal example for products is the Kodak singleuse camera, where the customer knows that the company utilizes used remanufacturing parts in the production of some cameras but does not know whether a specific product contains used parts or not. The manufacturer sells both new 


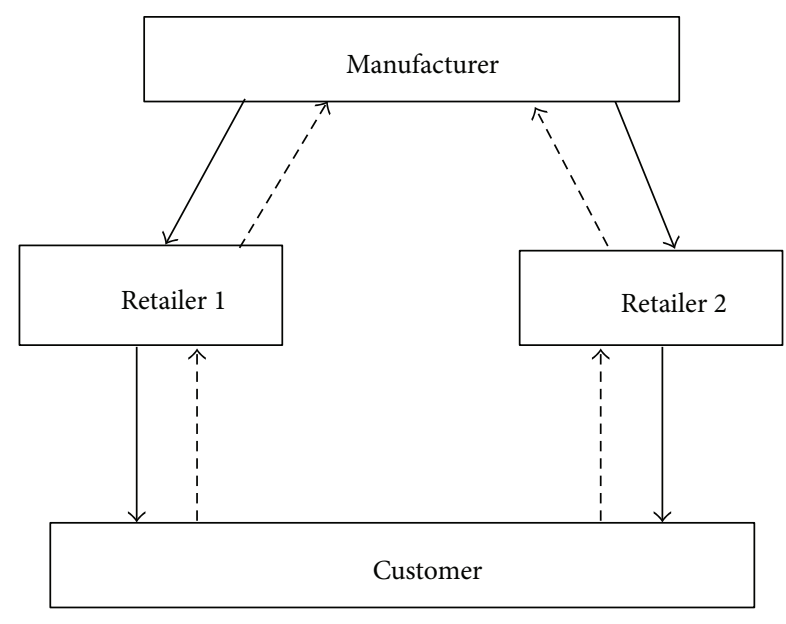

(a) Coordinated collection (model C)

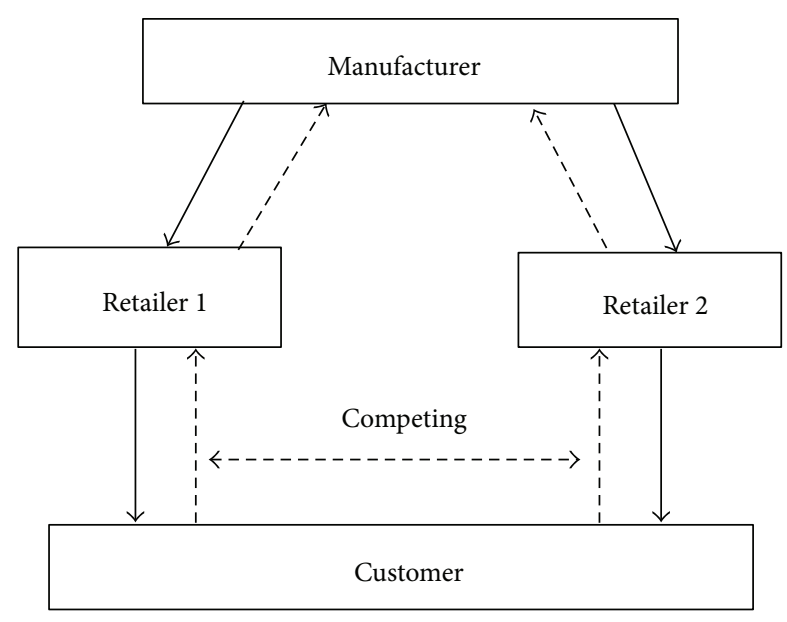

(b) Decentralized collection (model $D)$

FIgURE 1: Closed-loop supply channel structures.

and remanufactured products to the retailer at the same wholesale price $w$, who in turn sells both products at the same price $p$ on the market [23]. Let $c_{m}$ and $c_{r}$ denote the unit cost of manufacturing a new product and remanufacturing a returned product into a new one, respectively. Assume that $c_{r}<c_{m}$, which implies that the manufacturer can make savings from remanufacturing. Let $\Delta=c_{m}-c_{r}$ denote the unit saving cost by remanufacturing. We also add a Notations section to help the authors to understand and distinguish the notations.

Consistent with the existing literature [24], we assume that retailer $i$ faces the following linear demand function in the forward channel:

$$
D_{i}\left(p_{i}, p_{j}\right)=\Phi_{i}-p_{i}+\beta p_{j}, \quad 0 \leq \beta<1,
$$

where $\Phi_{i}$ represents the market size of retailer $i, p_{i}$ is the price of the product at retailer $i, p_{j}$ denotes the competitive retailer's retail price, and $\beta$ denotes the retailing substitution effect.

We assume that retailer $i$ faces the following recycling function in the reverse channel:

$$
Q_{i}\left(p_{R i}, p_{R j}\right)=\phi_{i}+p_{R i}-\gamma p_{R j}, \quad 0 \leq \gamma<1,
$$

where $\phi_{i}$ represents the market size of retailer $i$ by free recycling, $p_{R i}$ is the repurchase price of the used product at retailer $i, p_{R j}$ denotes the competitive retailer's repurchase price, and $\gamma$ denotes the recycling product recycling substitution effect.

Considering the relationship between the demand functions and recycling functions, we assume $\phi_{i}=s D_{i}\left(p_{i}, p_{j}\right)$, which denotes the market capacity which is recycled by the retailer freely, where $s$ is a recycling coefficient and $0 \leq s<1$ [25]. Ceteris paribus, the profit of retailing a new product is more than recycling obsolete products. So, we assume that the retailing substitution effect is more intense than the recycling substitution effect; that is, $0 \leq \gamma<\beta<1$, and $s$ is lower than the retailing substitution effect; that is, $0 \leq s<\beta<1$.
According to the above assumptions and notations, the channel's profit function in the case of coordinated collection is

$$
\begin{aligned}
\Pi^{C} & \left(p_{i}, p_{j}, p_{R i}, p_{R j}\right) \\
& =\sum_{i=1}^{2}\left(\left(p_{i}-c_{m}\right) D_{i}\left(p_{i}, p_{j}\right)+\left(\Delta-p_{R i}\right) Q_{i}\left(p_{i}, p_{R j}\right)\right),
\end{aligned}
$$

where $\sum_{i=1}^{2}\left(p_{i}-c_{m}\right) D_{i}\left(p_{i}, p_{j}\right)$ denotes the profit of the forward channel. Similarly, $\sum_{i=1}^{2}\left(\Delta-p_{R i}\right) Q_{i}\left(p_{R i}, p_{R j}\right)$ denotes the profit of the reverse channel.

The manufacturer profit function in the case of decentralized collection is

$$
\begin{aligned}
& \Pi_{m}^{D}\left(p_{i}, p_{j}, p_{R i}, p_{R j}\right) \\
& \quad=\sum_{i=1}^{2}\left(\left(w-c_{m}\right) D_{i}\left(p_{i}, p_{j}\right)+(\Delta-b) Q_{i}\left(p_{R i}, p_{R j}\right)\right),
\end{aligned}
$$

where $w$ represents the unit wholesale price and $b$ denotes the unit price of a returned product from the retailer to the manufacturer. $\left(w-c_{m}\right) \sum_{i=1}^{2} D_{i}\left(p_{i}, p_{j}\right)$ denotes the manufacturer's profit in the forward channel. Similarly, $(\Delta-$ b) $\sum_{i=1}^{2} Q_{i}\left(p_{R i}, p_{R j}\right)$ represents the manufacturer's profit in the reverse channel.

Each retailer's profit function in the case of decentralized collection is

$$
\Pi_{i}^{D}=\left(p_{i}-w\right) D_{i}\left(p_{i}, p_{j}\right)+\left(b-p_{R i}\right) Q_{i}\left(p_{R i}, p_{R j}\right),
$$

where $\left(p_{i}-w\right) D_{i}\left(p_{i}, p_{j}\right)$ denotes the profit of retailer $i$ in the forward channel and $\left(b-p_{R i}\right) Q_{i}\left(p_{R i}, p_{R j}\right)$ denotes the profit of retailer $i$ in the reverse channel. 


\section{Model Formulation and Solution}

In this section, two equilibrium models are discussed in the cases of coordinated collection and decentralized collection, respectively.

3.1. Coordinated Collection. According to (3), the coordinated collection model can be formulated as follows:

$$
\begin{aligned}
& \max _{p_{i}, p_{j}, p_{R i}, p_{R j}} \Pi^{C}\left(p_{i}, p_{j}, p_{R i}, p_{R j}\right) \\
& =\sum_{i=1}^{2}\left(\left(p_{i}-c_{m}\right) D_{i}\left(p_{i}, p_{j}\right)+\left(\Delta-p_{R i}\right) Q_{i}\left(p_{R i}, p_{R j}\right)\right) .
\end{aligned}
$$

Proposition 1. In the case of coordinated collection, the optimal retail $p_{i}^{C}$ and the optimal repurchase price $p_{j}^{C}$ satisfy

$$
\begin{aligned}
p_{i}^{* C}= & \frac{\left(\Phi_{i}+\Phi_{j} \beta\right)}{2\left(1-\beta^{2}\right)}+\frac{4\left(\Delta s-2 c_{m}\right)(1-\gamma)+s^{2}\left(\Phi_{i}+\Phi_{3-i}\right)}{4 X_{1}} \\
& -\frac{s^{2}\left(\Phi_{i}-\Phi_{3-i}\right)}{4 X_{2}}, \\
p_{R i}^{* C}= & \frac{\Delta}{2}+s\left[\frac{\left(\Phi_{i}+\Phi_{3-i}\right)-\left(2 c_{m}-\Delta s\right)(1-\beta)}{2 X_{1}}\right. \\
& \left.-\frac{\left(\Phi_{i}-\Phi_{3-i}\right)}{2 X_{2}}\right]
\end{aligned}
$$

where $X_{1}=s^{2}(1-\beta)-4(1-\gamma)$ and $X_{2}=-4(1-\gamma)-s^{2}(1+\beta)$.

Proof. According to (3), the second-order partial derivatives of $\Pi^{C}\left(p_{i}, p_{j}, p_{R i}, p_{R j}\right)$ are

$$
\begin{array}{rlrl}
\frac{\partial^{2} \Pi^{C}}{\partial p_{i}^{2}}=-2, & \frac{\partial^{2} \Pi^{C}}{\partial p_{i} \partial p_{j}}=2 \beta, & \frac{\partial^{2} \Pi^{C}}{\partial p_{i} \partial p_{R i}}=s, \\
& \frac{\partial^{2} \Pi^{C}}{\partial p_{i} \partial p_{R j}}=-s \beta, & \\
\frac{\partial^{2} \Pi^{C}}{\partial p_{j} \partial p_{i}}=2 \beta, & \frac{\partial^{2} \Pi^{C}}{\partial p_{j}^{2}}=-2, & \frac{\partial^{2} \Pi^{C}}{\partial p_{j} \partial p_{R i}}=-s \beta, \\
\frac{\partial^{2} \Pi^{C}}{\partial p_{R i} \partial p_{i}}=s, & \frac{\partial^{2} \Pi^{C}}{\partial p_{j} \partial p_{R j}}=s, & \frac{\partial^{2} \Pi^{C}}{\partial p_{R i} \partial p_{j}}=-s \beta, & \frac{\partial^{2} \Pi^{C}}{\partial p_{R i}^{2}}=-2, \\
\frac{\partial^{2} \Pi^{C}}{\partial p_{R j} \partial p_{i}}=-s \beta, & \frac{\partial^{2} \Pi^{C}}{\partial p_{R i} \partial p_{R j}}=2 \gamma, & \\
& \frac{\partial^{2} \Pi^{C}}{\partial p_{R j} \partial p_{j}}=s, & \frac{\partial^{2} \Pi^{C}}{\partial p_{R j} \partial p_{R i}}=2 \gamma, \\
\frac{\partial^{2} \Pi^{C}}{\partial p_{R j}^{2}}=-2 . &
\end{array}
$$

Then the Hessian matrix is

$$
|H|=\left|\begin{array}{cccc}
-2 & 2 \beta & s & -s \beta \\
2 \beta & -2 & -s \beta & s \\
s & -s \beta & -2 & 2 \gamma \\
-s \beta & s & 2 \gamma & -2
\end{array}\right| .
$$

By using the assumptions $0 \leq \gamma<\beta<1$ and $0 \leq s<\beta<$ 1 , we can obtain that $\left|D_{1}\right|=-2<0,\left|D_{2}\right|=4(1-\beta)>0$, $\left|D_{3}\right|=-2\left(1-\beta^{2}\right)\left(4-s^{2}\right)<0$, and $\left|D_{4}\right|=16+16\left(\gamma^{2}-\beta^{2}(1-\right.$ $\left.\left.\gamma^{2}\right)\right)+8 s^{2}\left(\beta^{2}+\gamma \beta\left(1-\beta^{2}\right)-1\right)+s^{4}\left(1-\beta^{2}\right)^{2}>0$. So $H$ is negative definite; $\Pi^{C}$ is jointly concave with respect to $p_{i}^{C}, p_{3-i}^{C}, p_{j}^{C}$, and $p_{3-j}^{C}$; thus, the optimal retailing and repurchase prices can be obtained by the first-order conditions as follows:

$$
\begin{aligned}
\frac{\partial \Pi^{C}}{\partial p_{i}} & =\Phi_{i}-2 p_{i}+2 \beta p_{j}+s p_{R i}-s \beta p_{R j}+(1-\beta)\left(c_{m}-s \Delta\right) \\
& =0, \\
& =0, \\
\frac{\partial \Pi^{C}}{\partial p_{j}} & =\Phi_{j}-2 p_{j}+2 \beta p_{i}+s p_{R i}-s \beta p_{R j}+(1-\beta)\left(c_{m}-s \Delta\right) \\
\frac{\partial \Pi^{C}}{\partial p_{R i}} & =-s \Phi_{i}+s p_{i}-s \beta p_{j}-2 p_{R i}+2 \gamma p_{R j}+(1-\gamma) \Delta \\
& =0,
\end{aligned}
$$

$\frac{\partial \Pi^{C}}{\partial p_{R j}}=-s \Phi_{j}+s p_{j}-s \beta p_{i}-2 p_{R j}+2 \gamma p_{R i}+(1-\gamma) \Delta$

$$
=0 \text {. }
$$

By combining (11), (12), (13), and (14) we can obtain the optimal retail prices $p_{i}^{*}$ and $p_{j}^{*}$, and optimal repurchase prices $p_{R i}^{*}$ and $p_{R j}^{*}$.

Corollary 2. In the case of coordinated collection, the retail prices $p_{i}^{C}$ and $p_{j}^{C}$ are strictly monotonically decreasing with respect to the recycling substitution effect.

Proof. According to (7), the first-order derivative of $p_{i}^{C}$ with respect to $\gamma$ is

$$
\begin{aligned}
\frac{\mathrm{d} p_{i}^{C}}{\mathrm{~d} \gamma}= & \left(s ^ { 2 } \left[X_{1}^{2}\left(\Phi_{i}-\Phi_{3-i}\right)\right.\right. \\
& \left.\left.\quad-X_{2}^{2}\left(\Phi_{i}+\Phi_{3-i}+(1-\beta)\left(\Delta s-2 c_{m}\right)\right)\right]\right) \\
& \times\left(X_{1}^{2} X_{2}^{2}\right)^{-1},
\end{aligned}
$$

where $X_{1}=s^{2}(1-\beta)-4(1-\gamma)$ and $X_{2}=-4(1-\gamma)-s^{2}(1+\beta)$.

It follows from the assumptions $0 \leq \gamma<\beta<1$ and $0 \leq s<$ $\beta<1$ that $\mathrm{d} p_{i}^{C} / \mathrm{d} \gamma<0$; thus, the retail prices $p_{i}^{C}$ and $p_{j}^{C}$ are strictly decreasing with respect to the recycling substitution effect. 
Corollary 3. In the case of coordinated collection, the repurchase prices $p_{R i}^{C}$ and $p_{R j}^{C}$ are strictly increasing with respect to the recycling substitution effect.

Proof. According to (8), the first-order derivative of $p_{R i}^{C}$ is

$$
\begin{gathered}
\frac{\mathrm{d} p_{R i}^{\mathrm{C}}}{\mathrm{d} \gamma}=2 s\left(X_{2}^{2}\left[\Phi_{i}+\Phi_{3-i}-\left(2 c_{m}-\Delta s\right)(1-\beta)\right]\right. \\
\left.-X_{1}^{2}\left(\Phi_{i}-\Phi_{3-i}\right)\right) \times\left(X_{1}^{2} X_{2}^{2}\right)^{-1},
\end{gathered}
$$

where $X_{1}=s^{2}(1-\beta)-4(1-\gamma)$ and $X_{2}=-4(1-\gamma)-s^{2}(1+\beta)$.

By assumptions $0 \leq \gamma<\beta<1$ and $0 \leq s<\beta<1$, we can obtain that $\mathrm{d} p_{j}^{C C} / \mathrm{d} \gamma>0$; thus, the repurchase prices $p_{R i}^{C}$ and $p_{R j}^{C}$ are strictly increasing with respect to the recycling substitution effect.

Corollary 2 implies how the recycling substitution effect impacts the profit of forward channel. Specially, the manufacturer can obtain more profit from forward channel by inducing recycling substitution effect (select the lower retail price to induce more recycling substitution effect). Corollary 3 implies how the recycling substitution effect impacts the profit of reverse channel; the manufacturer can select optimal repurchase price by inducing recycling substitution effect (inducing more recycling substitution effect to select the higher retail price) in order to obtain more profit of reverse channel. Corollaries 2 and 3 illustrate that the recycling substitution effect's impact on the profit of forward and reverse is converse, so the manufacturer can induce a suitable recycling substitution effect between the retailers to obtain the maximum profit in forward and reverse supply chain.

Proposition 4. In the case of coordinated collection, the profit of forward channel is strictly increasing with respect to the retailing substitution effect and decreasing with respect to the recycling substitution effect. While the profit of reverse channel is strictly decreasing with respect to the retailing substitution effect and increasing with respect to the recycling substitution effect.

Proof. First, for the analysis of the profit in forward channel, for any given $p_{j}$, according to (1), the demand $D_{i}$ is invariable for the durable product, and $\Phi_{i}$ is constant for retailer $i$; the retail price is increasing with respect to the retailing substitution effect. Then, it follows from (3) that the profit of forward channel $\sum_{i=1}^{2}\left(p_{i}-c_{m}\right) D_{i}\left(p_{i}, p_{j}\right)$ is increasing with respect to $p_{i}$ and $p_{j}$. Furthermore, by Corollary 2 , the retail prices $p_{i}$ and $p_{j}$ are both strictly decreasing with respect to the recycling substitution effect. Hence, the profit of forward channel function $\sum_{i=1}^{2}\left(p_{i}-c_{m}\right) D_{i}\left(p_{i}, p_{j}\right)$ is decreasing with respect to the recycling substitution effect.

Second, for the analysis of the profit in reverse channel, for any given $p_{R i}$, since the recycling function $Q_{i}$ is invariable for the durable product, and $\phi_{i}=s D_{i}$ and $p_{R i}$ are invariable for retailer $i$, by (2), the repurchase price is increasing with respect to recycling substitution effect. Then, the profit of reverse channel $\sum_{i=1}^{2}\left(\Delta-p_{R i}\right) Q_{i}\left(p_{R i}, p_{R j}\right)$ in (3) is decreasing with respect to $p_{R i}$ and $p_{R j}$. According to Corollary 3, the repurchase prices $p_{R i}$ and $p_{R j}$ are strictly increasing with respect to the recycling substitution effect. Therefore, the profit of reverse channel function $\sum_{i=1}^{2}\left(\Delta-p_{R i}\right) Q_{i}\left(p_{R i}, p_{R j}\right)$ is decreasing with the recycling substitution effect.

From what is discussed above, in the case of coordinated collection, we can obtain some managerial insights in practice. It is illustrated that the variation tendency of the forward channel profit is decided by the difference between the increase of forward channel profit from the retailing substitution effect and the decrease of forward channel's profit stemmed from the recycling substitution effect. Similarly, the variation of reverse channel profit is decided by the difference between the increase of reverse channel profit for the retailing substitution effect and the decrease of reverse channel profit for the recycling substitution effect. Additionally, the variation of the total profit of forward and reverse channel is uncertain. Furthermore, the manufacturer can induce lower retailing substitution effect and higher recovery substitution effect to collect more obsolete products and increase the profit of reverse channel. In other words, the manufacturer can easily achieve the goal of remanufacturing strategy by recovering the residual value of used products.

3.2. Decentralized Collection. In the case of decentralized collection, the manufacturer decides on the wholesale price $w$ and reimburses each retailer a fixed fee $b$ per unit returned, and the retailers compete with each other and decide on the retail price of the product as well as the repurchase price of collection used product.

We can obtain retailer $i$ 's reaction function by solving the following optimization problem:

$$
\max _{p_{i}, p_{j}} \Pi_{i}^{D}=\left(p_{i}-w\right) D_{i}\left(p_{i}, p_{j}\right)+\left(b-p_{R j}\right) Q_{R i}\left(p_{R i}, p_{R j}\right) .
$$

Proposition 5. In the case of decentralized collection, the retailer's optimal reaction retail price $p_{i}^{* D}$ and the optimal reaction repurchase price $p_{R i}^{* D}$ satisfy

$$
\begin{aligned}
p_{i}^{* D}= & \frac{b s(1-\gamma)-w(2-\gamma)}{Y_{11}}+\frac{\left(\Phi_{i}+\Phi_{3-i}\right) Y_{1}}{2 Y_{11}} \\
& +\frac{\left(\Phi_{i}-\Phi_{3-i}\right) Z_{1}}{2 Z_{11}}, \\
p_{R i}^{* D}= & \frac{s\left(\Phi_{i}+\Phi_{3-i}\right)}{2 Y_{11}}-\frac{s\left(\Phi_{i}-\Phi_{3-i}\right)}{2 Z_{11}} \\
& +b\left[\frac{s^{2}(1-\gamma)}{Y_{1} Y_{11}}+\frac{\left(1-s^{2}\right) Z_{1}}{T}\right] \\
& -w s\left[\frac{Z_{1}}{T}+(2-\gamma)\right],
\end{aligned}
$$

where $Y_{1}=s^{2}+\gamma-2, Y_{11}=s^{2}-2(2-\gamma)+\beta\left(2-s^{2}-\gamma\right)$, $Z_{1}=2+\gamma-s^{2}, Z_{11}=2(2+\gamma)-\beta\left(2+s^{2}-\gamma\right)-s^{2}$, and $T=\gamma^{2}-s^{4}-4\left(1-s^{2}\right)$. 
Proof. The second-order partial derivatives of retailer's profit $\Pi_{i}^{D}$ are

$$
\begin{array}{rlrl}
\frac{\partial^{2} \Pi_{i}^{D}}{\partial p_{i}^{2}}=-2, & & \frac{\partial^{2} \Pi_{i}^{D}}{\partial p_{i} \partial p_{j}}=s . \\
\frac{\partial^{2} \Pi_{i}^{D}}{\partial p_{j} \partial p_{i}}=s, & \frac{\partial^{2} \Pi_{i}^{D}}{\partial p_{j}^{2}}=-s \beta .
\end{array}
$$

Then the Hessian matrix is

$$
|H|=\left|\begin{array}{ll}
\frac{\partial^{2} \Pi_{i}^{D}}{\partial p_{i}^{2}} & \frac{\partial^{2} \Pi_{i}^{D}}{\partial p_{i} \partial p_{j}} \\
\frac{\partial^{2} \Pi_{i}^{D}}{\partial p_{j} \partial p_{i}} & \frac{\partial^{2} \Pi_{i}^{D}}{\partial p_{j}^{2}}
\end{array}\right| .
$$

By using the assumptions $0 \leq \gamma<\beta<1$ and $0 \leq s<$ $\beta<1$, we can obtain that $\left|D_{1}\right|=\partial^{2} \Pi_{i}^{D} / \partial p_{i}^{2}=-2<0$ and $\left|D_{2}\right|=2 s(\beta-s)>0$. So $H$ is negative definite; $\Pi^{D}$ is jointly concave with respect to $p_{i}$ and $p_{j}$. Thus, the optimal retailing and repurchase price can be obtained by the firstorder condition as follows.

According to (17), for retailer 1, the first-order conditions of $\Pi_{i}^{D}$ are

$$
\begin{gathered}
\frac{\partial \Pi_{i}^{D}}{\partial p_{i}}=\Phi_{i}-2 p_{i}+\beta p_{j}+w-s\left(b-p_{R i}\right)=0, \\
\frac{\partial \Pi_{i}^{D}}{\partial p_{R i}}=-s\left(\Phi_{i}-p_{i}+\beta p_{j}\right)-p_{R i}+\gamma p_{R j}+b-p_{R i}=0 .
\end{gathered}
$$

Similarly, for retailer 2, the first-order partial conditions of $\Pi_{j}^{D}$ are

$$
\begin{gathered}
\frac{\partial \Pi_{j}^{D}}{\partial p_{j}}=\Phi_{j}-2 p_{j}+\beta p_{i}+w-s\left(b-p_{R j}\right)=0 \\
\frac{\partial \Pi_{j}^{D}}{\partial p_{R j}}=-s\left(\Phi_{j}-p_{j}+\beta p_{i}\right)-p_{R j}+\gamma p_{R i}+b-p_{R j}=0 .
\end{gathered}
$$

By combining (22), (23), (24), and (25), we can obtain the optimal retail prices $p_{i}$ and $p_{j}$ and optimal repurchase prices $p_{R i}$ and $p_{R j}$.

Corollary 6. The retail price is increasing with respect to the wholesale price $w$ and decreasing with respect to the buy-back payment $b$. But the repurchase price is decreasing with respect to the wholesale price $w$ and increasing with respect to the buyback payment $b$.

Proof. By the assumptions $0 \leq \gamma<\beta<1$ and $0 \leq s<\beta<1$, we can easily obtain $Y_{1}=s^{2}+\gamma-2<0, Y_{11}=s^{2}-2(2-\gamma)+\beta(2-$ $\left.s^{2}-\gamma\right)<0, Z_{1}=2+\gamma-s^{2}>0$, and $T=\gamma^{2}-s^{4}-4\left(1-s^{2}\right)<0$. Thus, according to (18), we can obtain that the retail prices $p_{i}$ and $p_{j}$ are increasing with respect to the wholesale price $w$, while decreasing with respect to the buy-back payment $b$. And it follows from (19) that the repurchase prices $p_{R i}$ and $p_{R j}$ are decreasing with respect to the wholesale price $w$, while increasing with respect to the buy-back payment $b$.

Substituting (18) and (19) into (17) yields

$$
\begin{aligned}
\max _{w, b} \Pi_{m}^{D}= & \left(w-c_{m}\right) \sum_{i=1}^{2} D_{i}\left(p_{i}^{* D}, p_{j}^{* D}\right) \\
& +(\Delta-b) \sum_{i=1}^{2} Q_{i}\left(p_{R i}^{* D}, p_{R j}^{* D}\right) .
\end{aligned}
$$

Proposition 7. In the case of decentralized collection, the manufacturer's optimal wholesale price $w^{*}$ and optimal buyback payment $b^{*}$ satisfy

$$
\begin{aligned}
w^{*}= & \frac{\left(\Phi_{1}+\Phi_{2}\right)}{4(1-\beta)}+\frac{\gamma s^{2}\left[4 K_{2}-K_{1}\left(\Phi_{1}+\Phi_{2}\right)\right]}{4 K_{1}\left[K_{1}(\beta+1)+4(1-\gamma)\right]} \\
& +\frac{K_{3}(1-\gamma)}{K_{1}(2-\gamma)}, \\
b^{*}= & \frac{2 \Delta N_{1}+\gamma N_{2}+\beta \gamma\left(2 c_{m} s-4 \Delta\right)}{4 \beta\left(2-s^{2}\right)+2 \gamma\left(8-s^{2}\right)-2(2+\beta \gamma)\left(4-s^{2}\right)},
\end{aligned}
$$

where $K_{1}=4(\gamma-1)+s^{2}(2-\gamma), K_{2}=\left(2 c_{m}-\Delta s\right)(1-\gamma)$, $K_{3}=c_{m}\left(s^{2}-2\right)(\gamma-2)+2 \Delta \gamma s, N_{1}=\beta\left(2-s^{2}\right)-\left(4-s^{2}\right)$, and $N_{2}=8 \Delta+\left(\Phi_{1}+\Phi_{2}-2 c_{m}\right) s$.

Proof. The second-order partial derivatives of $\Pi_{m}^{D}$ are

$$
\begin{aligned}
& \frac{\partial^{2} \Pi_{m}^{D}}{\partial w^{2}}=\frac{4 s^{2}(2-\gamma)(1-\beta)(1-\gamma)}{\left(2-\gamma-s^{2}\right)\left[s^{2}(1-\beta)-(2-\beta)(2-\gamma)\right]} \\
& \frac{\partial^{2} \Pi_{m}^{D}}{\partial b^{2}}=\frac{4 s^{2}(2-\gamma)(1-\gamma)^{2}}{\left(2-\gamma-s^{2}\right)\left[s^{2}(1-\beta)-(2-\beta)(2-\gamma)\right]} \\
& \frac{\partial^{2} \Pi_{m}^{D}}{\partial w \partial b} \\
& =\frac{\partial^{2} \Pi_{m}^{D}}{\partial b \partial w} \quad \frac{4 s^{2}(2-\gamma)^{2}[1-\beta+2 s(1-\gamma)-(2-\beta)(2-\gamma)]}{\left(2-\gamma-s^{2}\right)\left[s^{2}(1-\beta)-(2-\beta)(2-\gamma)\right]} \\
& \quad\left|H_{m}\right|=\mid \begin{array}{ll}
\frac{\partial^{2} \Pi_{m}^{D}}{\partial w^{2}} & \frac{\partial^{2} \Pi_{m}^{D}}{\partial w \partial b} \\
\frac{\partial^{2} \Pi_{m}^{D}}{\partial b \partial w} & \frac{\partial^{2} \Pi_{m}^{D C}}{\partial b^{2}} \mid
\end{array}
\end{aligned}
$$

By the assumptions $0 \leq \gamma<\beta<1$ and $0 \leq s<\beta<1$, we can easily obtain that $H_{m}$ is negative definite, so $\Pi_{m}^{D}$ is jointly concave with respect to the wholesale price $w$ and buy-back 
payment $b$. Thus, the optimal wholesale price $w$ and buy-back payment $b$ can be obtained by the first-order condition.

According to (26), the first-order conditions of $\Pi_{m}^{D}$ with respect to $w$ and $b$ are as follows:

$$
\begin{aligned}
& \frac{\partial \Pi_{m}^{D}}{\partial w} \\
& \quad=\frac{2(2-\gamma)\left(2 w-b s+c_{m}\right)+2 \Delta s}{s^{2}+\gamma-2} \\
& \quad+\left(( \gamma - 2 ) \left[2 b s(1-\gamma)+\left(\Phi_{1}+\Phi_{2}\right)\left(s^{2}+\gamma-2\right)\right.\right. \\
& \quad+2 w(\gamma-2) \\
& \left.\left.\quad+2\left(c_{m}-w\right)(2-\gamma+2 s(b-\Delta))\right]\right) \\
& \quad \times\left(\left(s^{2}+\gamma-2\right)\left[2 \gamma-\beta\left(s^{2}+\gamma-2\right)+s^{2}-4\right]\right)^{-1}=0,
\end{aligned}
$$

$$
\begin{aligned}
& \frac{\partial \Pi_{m}^{D}}{\partial b} \\
& =\frac{2(1-\gamma)\left(2 b-\Delta+c_{m} s\right)-2 w s(2-\gamma)}{s^{2}+\gamma-2} \\
& \quad+\left(s \left[2 b s(1-\gamma)+\left(\Phi_{1}+\Phi_{2}\right)\left(s^{2}+\gamma-2\right)\right.\right. \\
& \quad+2 w(\gamma-2)] \\
& \left.\quad+2 s(1-\gamma)\left[\left(c_{m}-w\right)(2-\gamma)+s(b-\Delta)\right]\right) \\
& \quad \times\left(\left(s^{2}+\gamma-2\right)\left[2 \gamma-\beta\left(s^{2}+\gamma-2\right)+s^{2}-4\right]\right)^{-1}=0 .
\end{aligned}
$$

By combining (30) and (31), we can obtain the optimal retail wholesale price $w^{*}$ and buy-back payment $b^{*}$; that is, (27) and (28) hold.

Proposition 8. In the case of decentralized collection, the optimal retail $p_{i}^{* D}$ and optimal repurchase price $p_{R i}^{* D}$ of retailer $i$ satisfy

$$
\begin{aligned}
p_{i}^{* D} & \frac{\left(\Phi_{i}-\Phi_{3-i}\right)}{2}\left[\frac{Z_{1}}{Z_{11}}-\frac{Y_{1}}{Y_{11}}\right] \\
& +\frac{s(1-\gamma)}{2 Y_{11}}\left[\frac{2 \Delta M_{1}+\gamma M_{2}+2 \beta \gamma\left(c_{m} s-2 \Delta\right)}{2 M_{1}+\gamma M_{2}}\right]
\end{aligned}
$$

$$
\begin{aligned}
-\frac{(2-\gamma)}{Y_{11}}\left[\frac{\left(\Phi_{1}+\Phi_{2}\right)}{4(1-\beta)}+\frac{\gamma s^{2}\left[4 K_{2}-K_{1}\left(\Phi_{1}+\Phi_{2}\right)\right]}{4 K_{1}\left[K_{1}(1+\beta)+4(1-\gamma)\right]}\right. \\
\left.+\frac{K_{3}(1-\gamma)}{K_{1}(2-\gamma)}\right],
\end{aligned}
$$

$p_{R i}^{* D}$

$$
\begin{aligned}
= & \left(\frac{(1-\gamma) s^{2}}{Y_{1} Y_{11}}-\frac{\left(1-s^{2}\right) Z_{1}}{T}\right) \\
& \times\left(\frac{2 \Delta M_{1}+\gamma M_{3}+\beta \gamma\left(2 c_{m} s-4 \Delta\right)}{2 M_{1}+\gamma M_{2}}\right)-s\left[(2-\gamma)+\frac{Z_{1}}{T}\right] \\
& \times\left(\frac{\left(\Phi_{1}+\Phi_{2}\right)}{4(1-\beta)}+\frac{\gamma s^{2}\left[4 K_{2}-K_{1}\left(\Phi_{1}+\Phi_{2}\right)\right]}{4 K_{1}\left[K_{1}(\beta+1)+4(1-\gamma)\right]}\right. \\
& \left.+\frac{K_{3}(1-\gamma)}{K_{1}(2-\gamma)}\right)+\left[\frac{s\left(\Phi_{i}+\Phi_{3-i}\right)}{2}\right]\left(\frac{1}{Y_{11}}-\frac{1}{Z_{11}}\right),
\end{aligned}
$$

where $M_{1}=\beta\left(2-s^{2}\right)-\left(4-s^{2}\right), M_{2}=\left(8-s^{2}\right)-\beta\left(4-s^{2}\right)$, $M_{3}=8 \Delta+\left(\Phi_{1}+\Phi_{2}-2 c_{m}\right) s, K_{1}=4(\gamma-1)+s^{2}(2-\gamma)$, $K_{2}=\left(2 c_{m}-\Delta s\right)(1-\gamma), K_{3}=c_{m}\left(s^{2}-2\right)(\gamma-2)+2 \Delta \gamma s, N_{1}=$ $\beta\left(2-s^{2}\right)-\left(4-s^{2}\right), N_{2}=8 \Delta+\left(\Phi_{1}+\Phi_{2}-2 c_{m}\right) s, Y_{1}=s^{2}+\gamma-2$, $Y_{11}=s^{2}-2(2-\gamma)+\beta\left(2-s^{2}-\gamma\right), Z_{1}=2+\gamma-s^{2}, Z_{11}=$ $2(2+\gamma)-\beta\left(2+s^{2}-\gamma\right)-s^{2}$, and $T=\gamma^{2}-s^{4}-4\left(1-s^{2}\right)$.

Proof. By substituting (27) and (28) into (18) and (19), respectively, we can obtain the optimal retail price and repurchase price of retailer $i$.

Proposition 9. In the case of decentralized collection, the manufacturer's profit of forward channel is strictly increasing with respect to the retailing substitution effect and decreasing with respect to the recycling substitution effect, while the manufacturer's reverse channel's profit is increasing with respect to the retailing substitution effect and decreasing with respect to the recycling substitution effect.

Proof. First, we analyze the retailing substitution effect's impact on the manufacturer's profit in forward channel. According to (1), the demand of retailing $D_{i}$ is invariable for the durable product, and $\Phi_{i}$ and $p_{j}$ are invariable for retailer $i$; thus, the retail price is increasing with respect to the retailing substitution effect; that is, increasing the retailing substitution effect $\beta$ will induce the increase of retail price $p_{i}$, and according to Corollary 6 , it will induce the increase of wholesale price $w$. According to (4), the manufacturer's profit in forward channel $\left(w-c_{m}\right)\left(D_{i}\left(p_{i}, p_{j}\right)+\right.$ $\left.D_{j}\left(p_{j}, p_{i}\right)\right)$ is increasing with respect to retailing substitution effect. Similarly, we can easily obtain that the manufacturer's profit in forward channel $\left(w-c_{m}\right)\left(D_{i}\left(p_{i}, p_{j}\right)+D_{j}\left(p_{j}, p_{i}\right)\right)$ is decreasing with respect to recycling substitution effect.

Second, we analyze the retailing substitution effect's impact on the manufacturer's profit in reverse channel. According to (2), the recycling function $Q_{i}$ is invariable for the durable product, and $\phi_{i}=s D_{i}$ and $p_{R j}$ are invariable 
for retailer $i$; thus, the repurchase price is increasing with respect to recycling substitution effect. Then we can easily obtain that the increase of retailing substitution effect $\beta$ will induce the increase of retail price $p_{i}$, and according to Corollary 6, it will induce the decrease of buy-back payment $b$. According to (4), the manufacturer's reverse channel $(\Delta-b)\left(Q_{i}\left(p_{R i}, p_{R j}\right)+Q_{j}\left(p_{R j}, p_{R i}\right)\right)$ is increasing with respect to retailing substitution effect. Similarly, we can easily get that the manufacturer's reverse channel profit $(\Delta-$ b) $\left(Q_{i}\left(p_{R i}, p_{R j}\right)+Q_{j}\left(p_{R j}, p_{R i}\right)\right)$ is decreasing with respect to recycling substitution effect.

It is illustrated that in the case of decentralized collection, the variation of manufacturer's profit in forward or reverse channel is decided by the difference between the increase of forward or reverse channel profit for the retailing substitution effect and the decrease of forward and reverse channel profit for the recycling substitution effect. Additionally, the change of closed-loop supply chain's profit with respect to the retailing and recycling substitution effects is uncertain in the case of decentralized collection. On the other hand, the manufacturer can induce higher retailing substitution effect and lower recovery substitution effect via choosing suitable wholesale price and buy-back payment to collect more obsolete products and increase the profit of reverse channel. It means that the manufacturers can achieve their goal of remanufacturing strategy by recovering the residual value of used products.

Proposition 10. In the case of decentralized collection, the retailer's profit of forward channel is strictly increasing with respect to the retailing substitution effect and decreasing with respect to the recycling substitution effect, while his reverse channel profit is decreasing with respect to the retailing substitution effect and recycling substitution effect.

Proof. First, we analyze the retailing substitution effect's impact on the retailer's profit in forward channel. According to (1), the demand of retailing $D_{i}$ is invariable for the durable product, and $\Phi_{i}$ and $p_{j}$ are invariable for retailer $i$; thus, the retail price is increasing with respect to the retailing substitution effect,; that is, the increase of $\beta$ will induce the increase of retail price $p_{i}$. According to (5) each retailer's profit in forward channel $\left(p_{i}-w\right) D_{i}\left(p_{i}, p_{j}\right)$ is increasing with respect to the retailing substitution effect, similarly for retailer $j$. We can easily obtain that each retailer's profit in reverse channel $\left(p_{i}-w\right) D_{i}\left(p_{i}, p_{j}\right)$ is increasing with respect to recycling substitution effect.

Second, we analyze the retailing substitution effect's impact on the retailer's profit in reverse channel. According to (2), the recycling function $Q_{R i}$ is invariable for the durable product, and $\phi_{i}=s D_{i}$ and $p_{R j}$ are invariable for retailer $i$; thus, the repurchase price is increasing with respect to recycling substitution effect. Then we can easily obtain that the repurchase price is increasing with respect to recycling substitution effect. So the increase of retailing substitution effect $\beta$ will induce the increase of retail price $p_{i}$, induce the increase of buy-back payment $b$, and then will induce the decrease of $p_{R i}$. According to (5), the retailer i's profit in reverse channel $\left(b-p_{R i}\right) Q_{i}\left(p_{R i}, p_{R j}\right)$ is decreasing with respect to retailing substitution effect. Similarly, we can easily get that the retailer $i$ 's profit in reverse channel $\left(b-p_{R i}\right) Q_{i}\left(p_{R i}, p_{R j}\right)$ is increasing with respect to recycling substitution effect.

Proposition 10 illustrates that, in the case of decentralized collection, the variation of retailer's profit in forward channel is decided by the difference between the increase of forward channel's profit for the retailing substitution effect and the decrease of forward channel profit for the recycling substitution effect. While, for the retailer's profit in reverse channel, it is decreasing with respect to retailing substitution effect and recycling substitution effect. Additionally, because the change of forward channel profit is uncertain, the variation of the closed-loop supply chain's profit is also uncertain. In this case, the retailer can induce lower retailing substitution effect and recovery substitution effect via choosing suitable wholesale price and buy-back payment to collect more obsolete products and increase the profit of reverse channel.

In a word, the variations of manufacturer and retailer's respective profit with the retailing substitution effect in forward channel are uniform, but in the reverse channel they are inconsistent. For example, the higher recycling substitution effect will induce the manufacturer to get more profits in reverse channel (i.e., augments the scale of the manufacturer's reverse supply chains). But the higher recycling substitution effect will cause the retailer to obtain less profits in reverse channel (i.e., cut down the scale of the retailer's reverse supply chains). There is a contradiction between the profits of the manufacturer and the retailer in reverse channel, because the manufacturer has sufficient channel power over the retailers to act as a Stackelberg leader; thus the manufacturer can choose the appropriate wholesale price and buy-back payment to achieve the remanufacturing strategy and balance the retailer's profit. And we make a comparison with the coordinated collection; we can easily know that the coordinated collection is more effective to augment the scale of the whole reverse supply chains than decentralized collection.

\section{Numerical Examples}

In this section, numerical examples are provided to compare the results obtained in the above two different collection models and to analyze the impacts of retailing and recycling substitution effects on the decisions and profits of chain members. Some managerial insights can be derived through the numerical analysis. The numerical analysis is performed for $\Phi_{1}=100, \Phi_{2}=50, c_{m}=20, \Delta=10, \gamma=0.4$ or $\gamma=0.2$, and $s=0.1$.

4.1. Numerical Analysis of Model C. In this subsection, we discuss the impacts of retailing and recycling substitution effects on the retail price, repurchase price, the forward channel profit, and reverse channel profit in the case of coordinated collection, respectively.

From the previous assumptions and analysis, we know that the retail price is strictly increasing with respect to retailing substitution effect; that is, the higher retailing substitution 


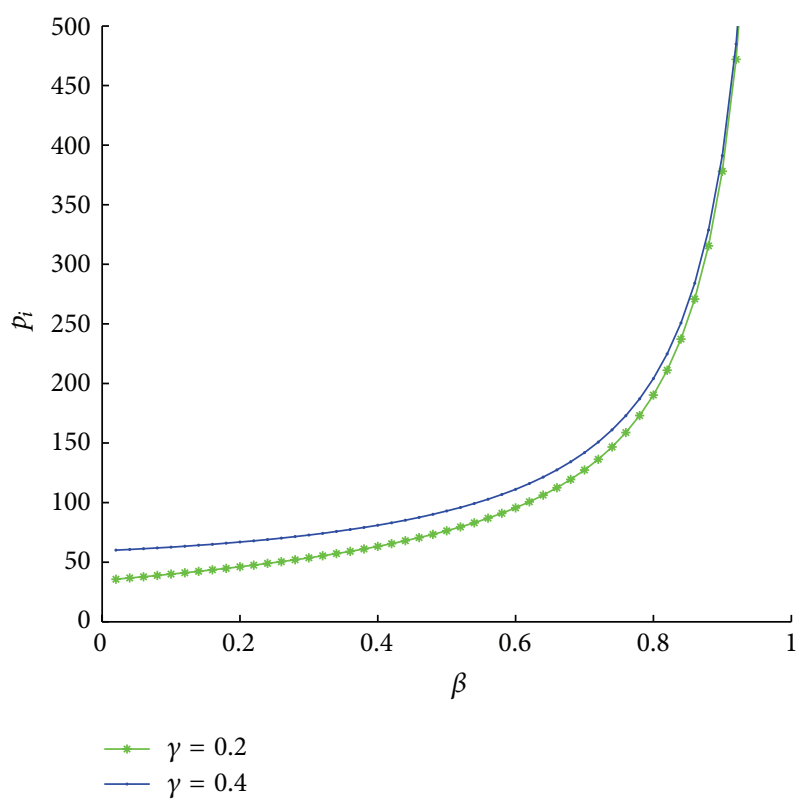

(a) Impact on the retail price

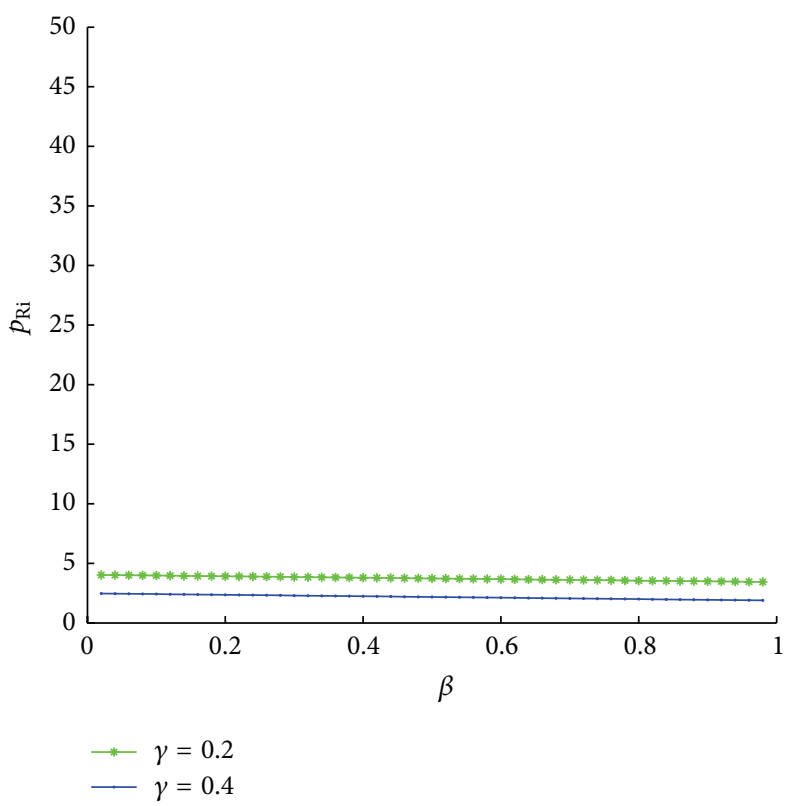

(b) Impact on the repurchase price

FIGURE 2: Impact of the retailing and recycling substitution effects on price in model $C$.

effect will induce the increase of retail price. Moreover, the higher recycling substitution effect will induce the increase of retail price; the higher recycling substitution effect will induce the decrease of repurchase price. In addition, the higher retailing substitution effect will induce the decrease of retail price. The green and blue lines in Figures 2(a) and 2(b) give us a visual presentation.

From the previous assumptions and analysis, we know that the profit of forward channel is strictly increasing with respect to retailing substitution effect and decreasing with respect to recycling substitution effect; that is, the manufacturer can induce higher retailing competition and lower recycling competition to obtain more profit from forward channel.

And we known that the profit of reverse channel is strictly decreasing with respect to retailing substitution effect and increasing with respect to recycling substitution effect; that is, the manufacturer can induce lower recycling substitution effect to obtain more profit in the reverse channel. In other words, the manufacturer can induce higher retailing substitution effect and lower recycling substitution effect could obtain more profit in closed-loop supply chain. The green and blue lines in Figures 3(a) and 3(b) give us a visual presentation.

4.2. Numerical Analysis of Model D. In this subsection, we discuss the impacts of retailing and recycling substitution effects on the retail price, repurchase price, the forward channel profit, and reverse channel profit in the case of decentralized collection, respectively.

From the previous assumptions and analysis, we know that the retail price is strictly increasing with respect to retailing substitution effect; that is, the higher retailing substitution effect will induce the increase of retail price. And the higher recycling substitution effect will induce the decrease of retail price. And we known that the repurchase price is strictly decreasing with respect to recycling substitution effect; that is, the higher recycling substitution effect will induce the increase of repurchase price, while the higher retailing substitution effect will induce the decrease of retail price. The green and blue lines in Figures 4(a) and 4(b) give us a visual presentation.

According to the assumptions and the analysis, we know that the manufacturer's profit of forward channel is strictly increasing with respect to retailing substitution effect and decreasing with respect to recycling substitution effect. And the manufacturer's profit of reverse channel is strictly decreasing with respect to retailing substitution effect and recycling substitution effect. In other words, in the case of decentralized collection, the manufacturer can induce higher retailing competition and lower recycling competition to obtain more profit in the forward channel and induce lower recycling substitution effect to obtain more profit in the the reverse channel. So, the manufacturer can select higher retailing substitution effect and lower recycling substitution effect to obtain more profit in their closed-loop supply chain. Moreover, the higher recycling competition will induce the lower profit of forward channel and induce lower profit of reverse channel.

For the forward channel profit of retailers is strictly increasing with respect to retailing substitution effect and decreasing with respect to recycling substitution effect. And the retailers' profit of reverse channel is strictly decreasing with respect to retailing substitution effect and increasing with respect to recycling substitution effect. In other words, in the case of decentralized collection, for the retailers, the higher retailing competition and lower recycling competition 


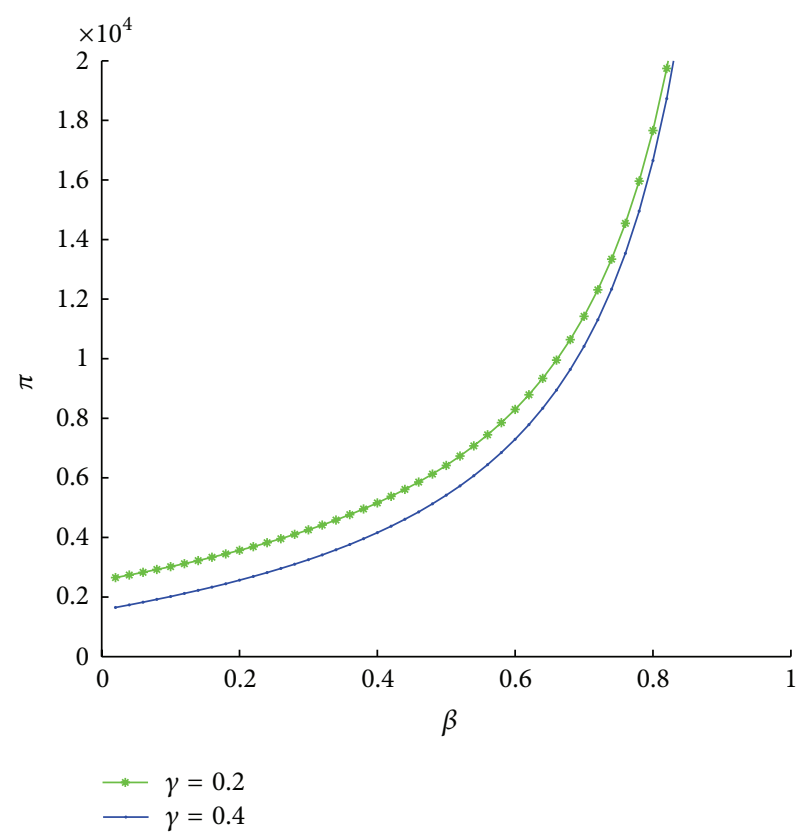

(a) Impact on the profit in forward channel

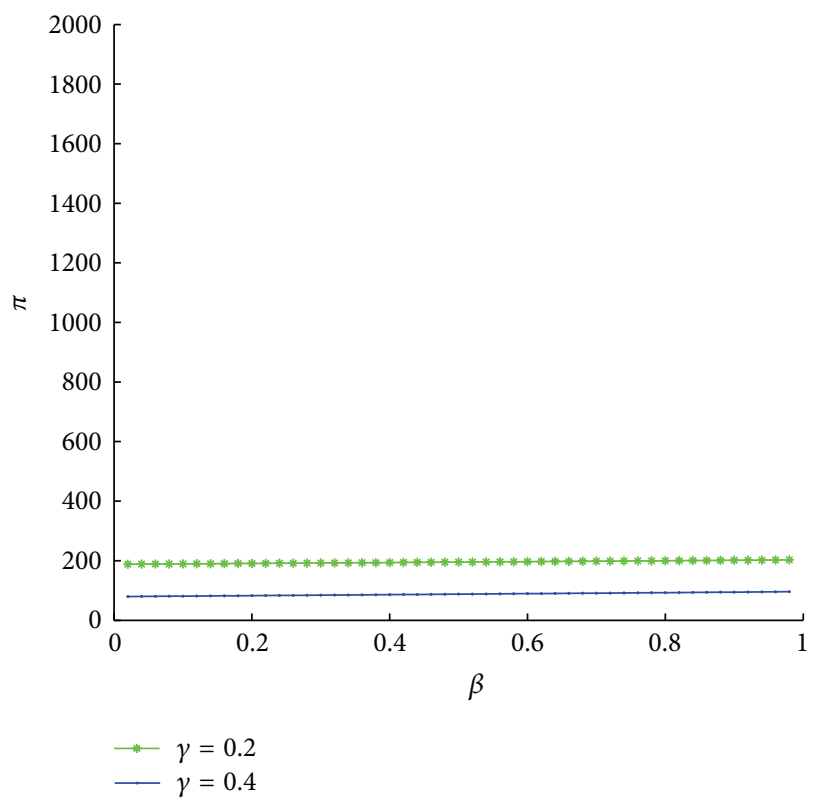

(b) Impact on the profit in reverse channel

FIGURE 3: Impact of the retailing and recycling substitution effects on channel profit in model $C$.

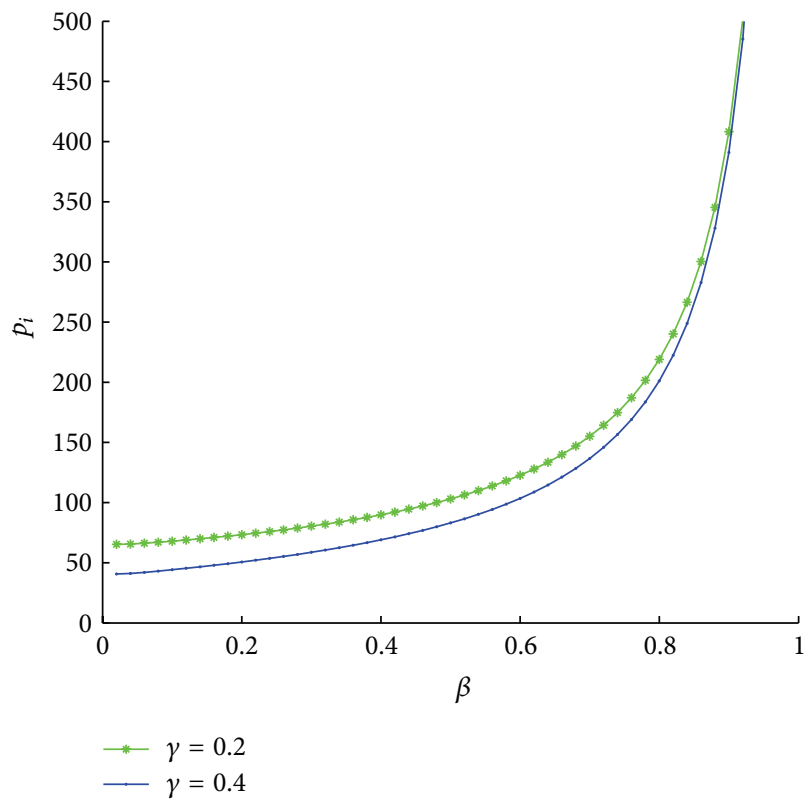

(a) Impact on the retail price

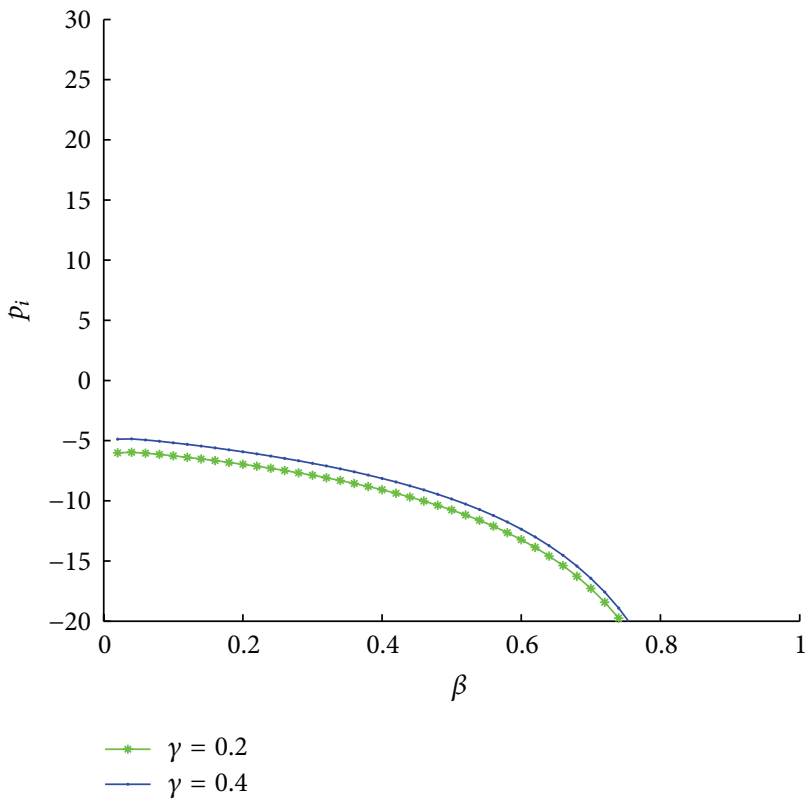

(b) Impact on the repurchase price

FIGURE 4: Impact of the retailing and recycling substitution effects on price in model $D$.

can make them obtain more profit in their forward channel, but the lower retailing substitution effect and higher recycling substitution effect can make them obtain more profit in the reverse channel. So, the retailers tend to select suitable retail price and repurchase price to induce retailing and recycling competitions (not too high or too low, the higher retail substitution effect will make the profit of reverse channel negative or the lower recycling substitution effect will make the profit of forward channel decrease) to obtain more profit in their closed-loop supply chain. The lines in Figure 5 give us a visual presentation.

4.3. Comparison of Model C and Model D. In this subsection, we discuss the impact of retailing substitution effect on the 


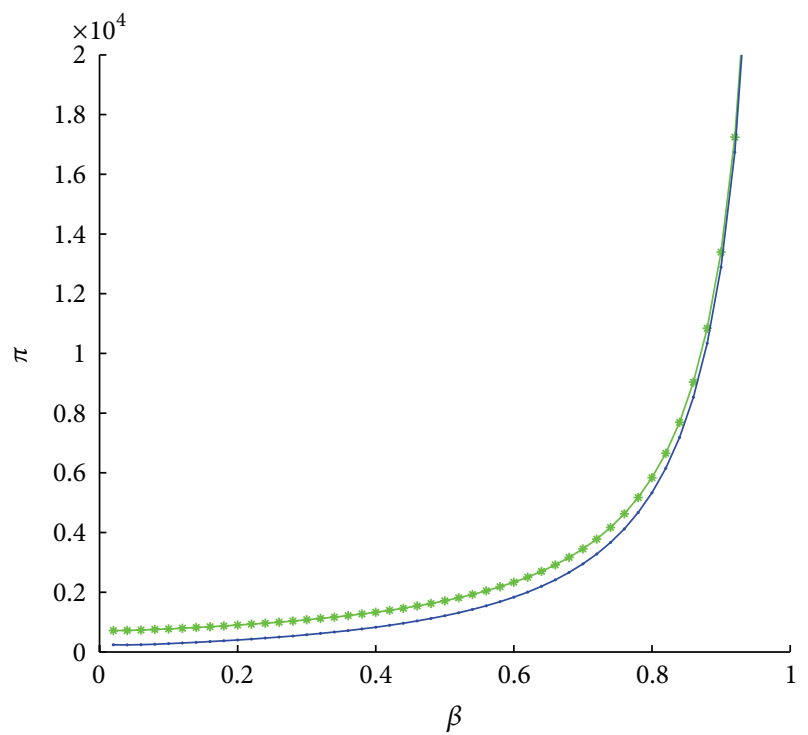

(a) Impact on the manufacturer's profit in forward channel

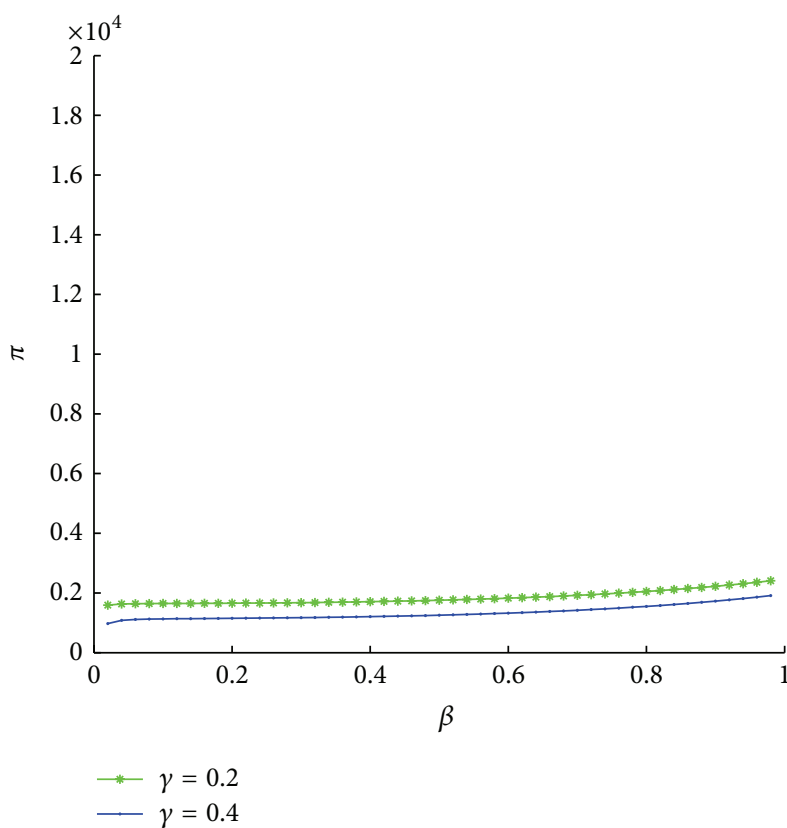

(c) Impact on the retailers' profit in forward channel

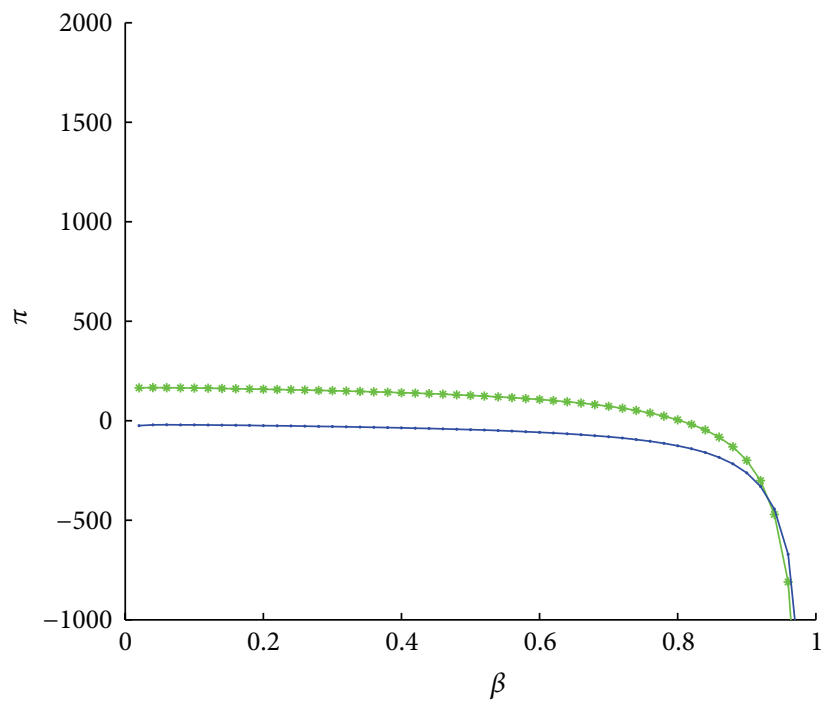

(b) Impact on the manufacturer's profit in reverse channel

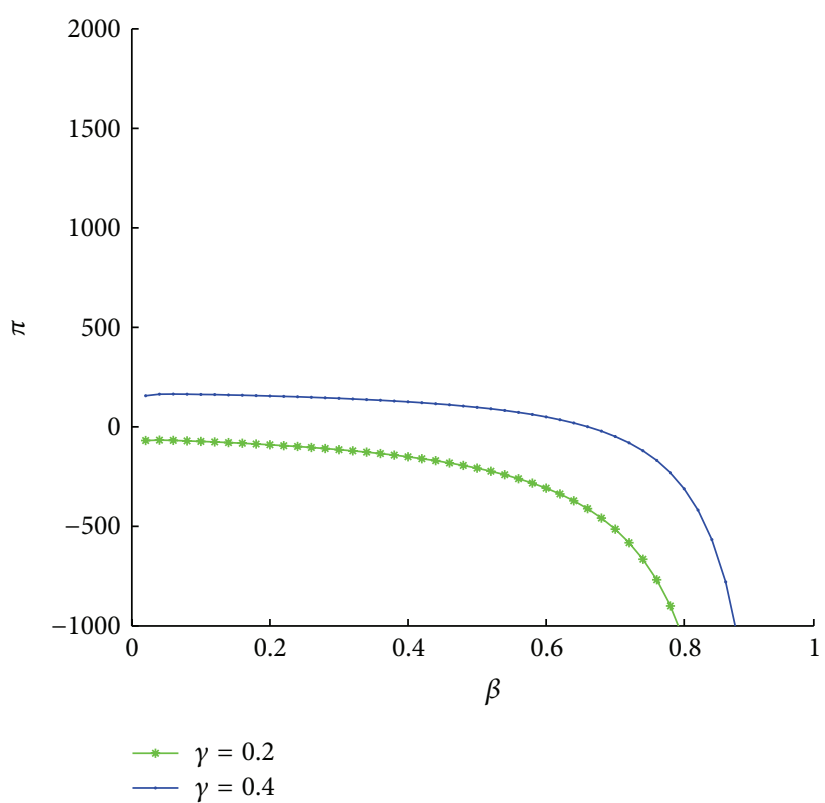

(d) Impact on the retailers' profit in reverse channel

FIGURE 5: Impact of the retailing and recycling substitution effects on channel profit in model DC.

optimal prices and optimal channel profits and compare them in the case of coordinated collection with that of decentralized collection.

From the previous assumptions and analysis, we know that the retail price in the case of coordinated collection is lower than that in decentralized collection; that is, facing the same circumstances, the retail price in the case of decentralized collection is higher than that in coordinated collection. And the repurchase price in the case of decentralized collection is lower than that in coordinated collection. It implies that, for the retailer, the coordinated collection has more price advantages (lower retail price and higher repurchase price) than the decentralized collection in the closed-loop channel. The lines in Figure 6 give us a visual presentation.

In what is discussed above, we know that the channel profit in model $C$ is higher than that in model $D$. The profit of reverse channel in model $D$ is very low; even the value is negative. In this case, the manufacturer and retailers tend to select coordinated collection to obtain more profits; for example, HP, Xerox, and Apple select the coordinated collection to collect their used product. The lines in Figure 6 give us a visual presentation.

4.4. Impact of Retailing and Recycling Substitution Effects on Closed Supply Chain's Profit. In this subsection, we discuss 


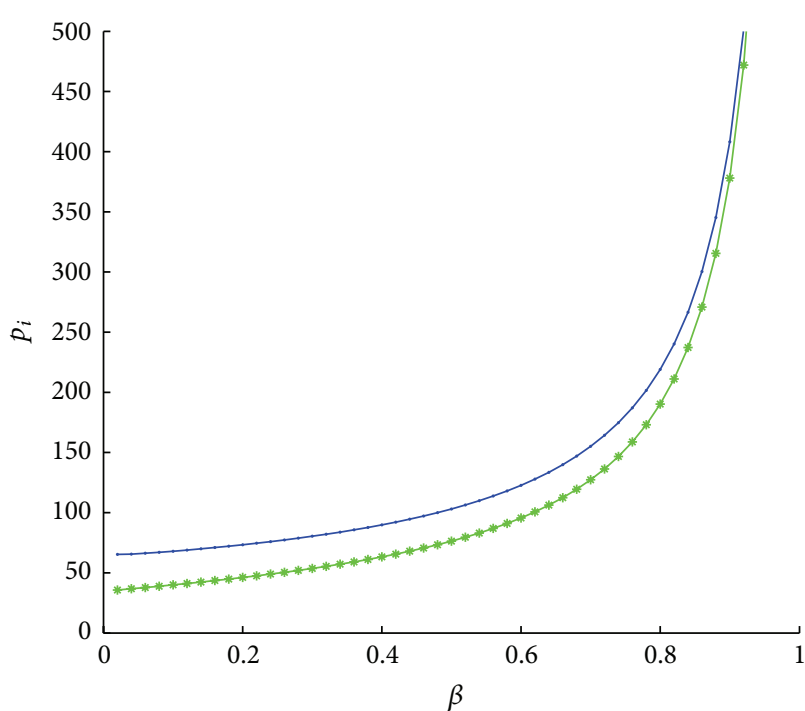

$\rightarrow$ Model CC — Model DC

(a) Comparison of retail price

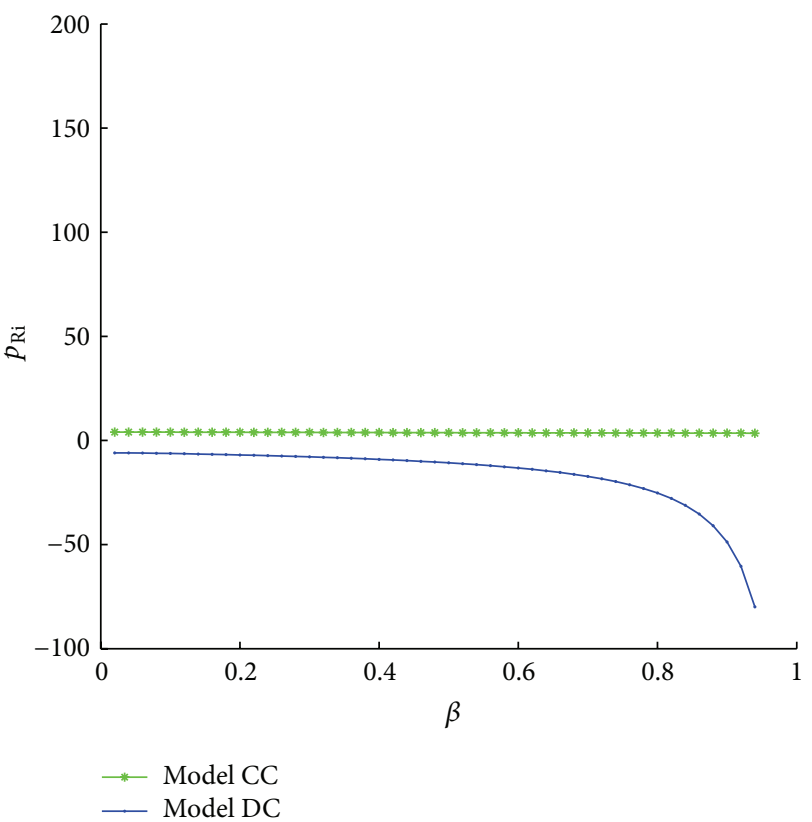

(b) Comparison of repurchase price

Figure 6: Pricing decisions of coordinated collection versus decentralized collection.

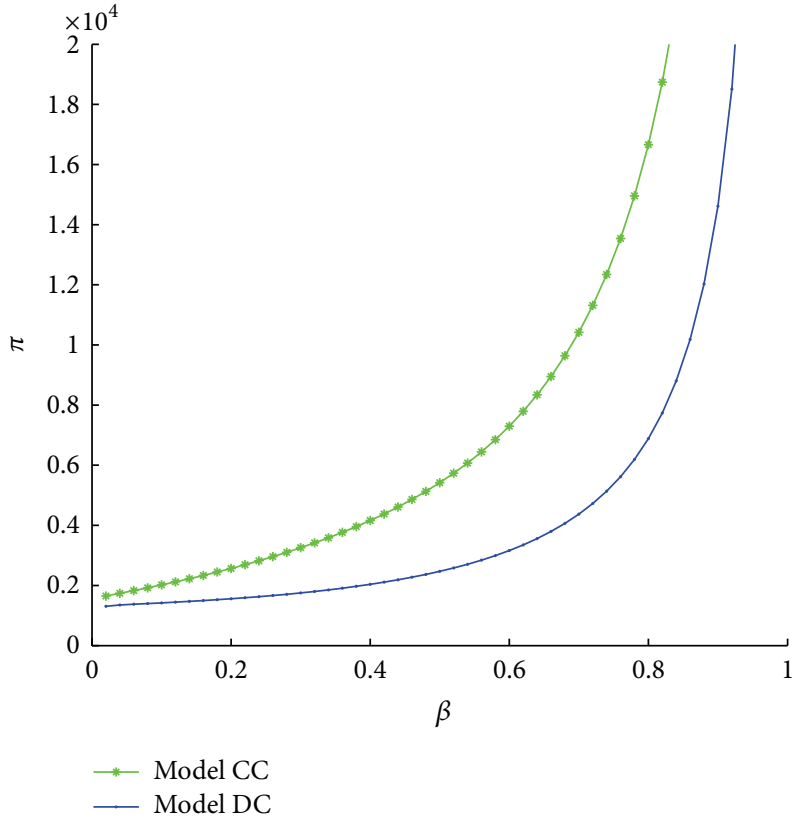

(a) Comparison of forward channel profits

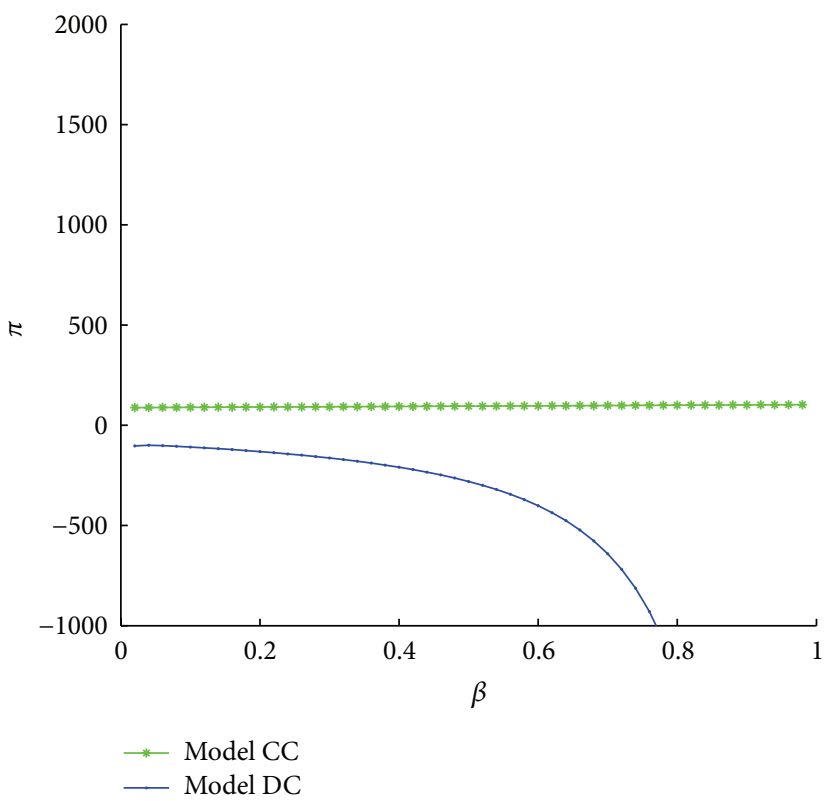

(b) Comparison of reverse channel profits

FIGURE 7: The profit of coordinated collection versus decentralized collection.

the impact of retailing and recycling substitution effects on the optimal forward channel profits and optimal reverse channel profits in the cases of coordinated collection and decentralized collection.

From the previous assumptions and analysis, we know that the recycling substitution effect's impact on the closed-loop supply channel profit in the case of coordinated collection is more obvious than that in decentralized collection. In other words, the manufacturer can obtain more profit than in decentralized collection more easily by changing the recycling substitution effect. The reason may be as follows: in the case of coordinated collection, the retail price and repurchase price are made by the center planner (i.e., manufacturer); this collection model can adjust the 


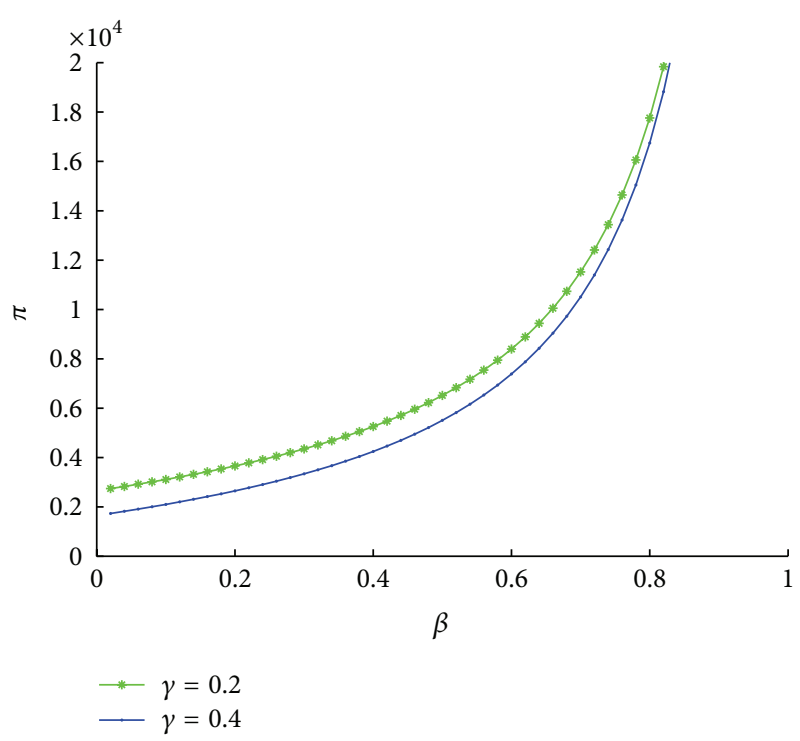

(a) Impact on the closed-loop supply channel's profit in model CC

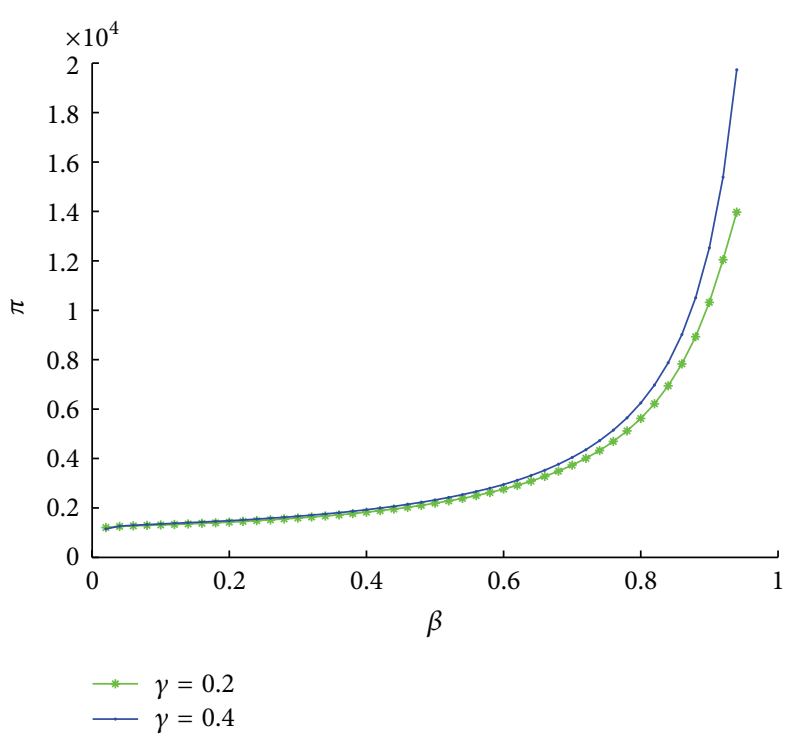

(b) Impact on the closed-loop supply channel's profit in model DC

FIGURE 8: Impact of the retailing and recycling substitution effects on closed-Loop supply chain's profit.

retail and repurchase price fast and accurately. But in case of decentralized collection, there is a pricing game between manufacturer and retailers. The manufacturer firstly selects optimal wholesale price and buy-back payment; then the retailers select their optimal reaction retail price and repurchase price; that is, the pricing game and pricing decision are unsynchronized between the manufacturer and retailer, so the manufacturer can obtain more profits in the case of coordinated collection than the case of decentralized collection. The lines in Figures 7 and 8 give us a visual presentation.

\section{Conclusion}

In this paper, we investigated a durable product retailing and recycling problem in a closed-loop supply chain consisting of a single manufacturer and two competitive retailers. The results demonstrate that more intense retailing competition induces the increase of the forward and reverse profits of manufacturer and the forward channel of retailers and decrease of the retailers profit in reverse channel, while more intense recycling competition induces the decrease of the profits of the manufacturer and retailers in forward and reverse channels, while the whole supply chain's profit of model $C$ is increasing with the respect to the free recycling proportional coefficient, but the effect on model $D$ is uncertain. The results have important managerial insights for the manufacturer and retailers.

This paper makes a contribution to the literature on reverse channel choice and coordination by drawing attention to closed-loop supply chains with competition of retailing and recycling. Our future research will be as follows: our model does not consider any fixed costs of retailing/recycling a collection system. If such costs were incurred, a minimum number of retailing/returns would be required to justify the cost of operations. Last but not least, our cost formulation

does not include any operational/capacity constraints in the channel of products collection. Operational/capacity constraint on the channel of collection can be incorporated into the model by defining an upper bound on the number collected via each channel. Another possibility is to model the collection cost as a quadratic function of the quantity returned.

\section{Notations}

$\gamma:$

$\beta$ :

$\Phi$ :

$\phi:$

$\delta:$

$s:$

$c_{r}:$

$c_{m}:$

$w:$

$b:$

$D_{i}\left(p_{i}, p_{j}\right): \quad$ Demand function of retailer $i$

$Q_{i}\left(p_{R i}, p_{R j}\right)$ : Recycling function of retailer $i$

$p_{i}^{C}, p_{j}^{D}: \quad$ Retailer $i$ and $j$ 's respective retail price in

$p_{R i}^{C}, p_{R j}^{D}$ :

$\Pi_{i}^{K}:$ retailers to the manufacturer

Recycling substitution effect

Retailing substitution effect

Market size of the retailers in the forward channel

Market size of the retailers by free recovering in the reverse channel

Unit saving cost by remanufacturing

Recovering coefficient

Unit cost of remanufacturing a returned product into a new one Unit cost of manufacturing a new product New product's wholesale price of the manufacturer models $C$ and $D$

Retailer $i$ and $j$ 's repurchase price in models $C$ and $D$

Profit function for channel member $i$ in model $k$. Superscript $k$ takes the values of $C$ and $D$. Subscript $i$ takes the values of $m, r$, and $e$, denoting the manufacturer, the retailer, and the $e$-tailer, respectively. 


\section{Conflict of Interests}

The authors declare that there is no conflict of interests regarding the publication of this paper.

\section{Acknowledgments}

The authors are grateful to the referees for their useful comments and suggestions, which improved the presentation of the paper. This work is supported by the Humanity and Social Science Foundation of Ministry of Education, China, no. 12YJAZH052 and the National Natural Science Foundation of China under Grant no. 71301114.

\section{References}

[1] R. C. Savaskan, S. Bhattacharya, and L. N. Van Wassenhove, "Closed-loop supply chain models with product remanufacturing," Management Science, vol. 50, no. 2, pp. 239-252, 2004.

[2] Pconline.com website, 2012, http://office.pconline.com.cn/huanbao/1206/2812375.html

[3] L. Debo, L. Toktay, and L. van Wassenhove, "Market segmentation and product technology selection for remanufacturable products," Management Science, vol. 51, no. 8, pp. 1193-1205, 2002.

[4] V. D. R. Guide Jr., R. H. Teunter, and L. N. van Wassenhove, "Matching demand and supply to maximiz e profits from remanufacturing," Manufacturing and Service Operations Management, vol. 5, no. 4, pp. 303-316, 2003.

[5] J. D. Shulman and A. T. Coughlan, "Used goods, not used bads: profitable secondary market sales for a durable goods channel," Quantitative Marketing and Economics, vol. 5, no. 2, pp. 191-210, 2007.

[6] S. Yin, S. Ray, H. Gurnani, and A. Animesh, "Durable products with multiple used goods markets: product upgrade and retail pricing implications," Marketing Science, vol. 29, no. 3, pp. 540560,2010

[7] T. Choi, D. Li, and H. Yan, "Optimal returns policy for supply chain with e-marketplace," International Journal of Production Economics, vol. 88, no. 2, pp. 205-227, 2004.

[8] B. Yalabik, N. C. Petruzzi, and D. Chhajed, "An integrated product returns model with logistics and marketing coordination," European Journal of Operational Research, vol. 161, no. 1, pp. 162182, 2005.

[9] Y. Liang, S. Pokharel, and G. H. Lim, "Pricing used products for remanufacturing," European Journal of Operational Research, vol. 193, no. 2, pp. 390-395, 2009.

[10] K. Inderfurth, "Optimal policies in hybrid manufacturing/ remanufacturing systems with product substitution," International Journal of Production Economics, vol. 90, no. 3, pp. 325343, 2004.

[11] R. C. Savaskan and L. N. van Wassenhove, "Reverse channel design: the case of competing retailers," Management Science, vol. 52, no. 1, pp. 1-14, 2006.

[12] E. Ofek, Z. Katona, and M. Sarvary, “'Bricks and clicks': the impact of product returns on the strategies of multichannel retailers," Marketing Science, vol. 30, no. 1, pp. 42-60, 2011.

[13] X. Hong, Z. Wang, D. Wang, and H. Zhang, "Decision models of closed-loop supply chain with remanufacturing under hybrid dual-channel collection," International Journal of Advanced Manufacturing Technology, vol. 68, no. 5-8, pp. 1851-1865, 2013.
[14] T. Choi, Y. Li, and L. Xu, "Channel leadership, performance and coordination in closed loop supply chains," International Journal of Production Economics, vol. 146, no. 1, pp. 371-380, 2013.

[15] S. Webster and S. Mitra, "Competitive strategy in remanufacturing and the impact of take-back laws," Journal of Operations Management, vol. 25, no. 6, pp. 1123-1140, 2007.

[16] M. E. Ferguson and L. B. Toktay, "The effect of competition on recovery strategies," Production and Operations Management, vol. 15, no. 3, pp. 351-368, 2006.

[17] C. Wu, "OEM product design in a price competition with remanufactured product," Omega, vol. 41, no. 2, pp. 287-298, 2013.

[18] S. Tayur and R. Ganeshan, Quantitative Models for Supply Chain Management, Kluwer Academic Publishers, Boston, Mass, USA, 1998.

[19] P. Majumder and H. Groenevelt, "Competition in remanufacturing," Production and Operations Management, vol. 10, no. 2, pp. 125-141, 2001.

[20] K. Hickey, "Here and there," Traffic World Magazine, vol. 265, no. 40 , p. $21,2001$.

[21] K. S. Jung and H. Hwang, "Competition and cooperation in a remanufacturing system with take-back requirement," Journal of Intelligent Manufacturing, vol. 22, no. 3, pp. 427-433, 2011.

[22] C.-C. Chern, S.-T. Lei, and K.-L. Huang, "Solving a multiobjective master planning problem with substitution and a recycling process for a capacitated multi-commodity supply chain network," Journal of Intelligent Manufacturing, vol. 25, no. 1, pp. 1-25, 2014.

[23] L. van Wassenhove, A. Atasu, and L. Toktay, "How collection cost structure drives a manufacturer's reverse channel choice," Production and Operations Management, vol. 22, no. 5, pp.10891102, 2013.

[24] E. Lee and R. Staelin, "Vertical strategic interaction: implications for channel pricing strategy," Marketing Science, vol. 16, no. 3, pp. 185-207, 1997.

[25] I. Dobos and K. Richter, "A production/recycling model with quality consideration," International Journal of Production Economics, vol. 104, no. 2, pp. 571-579, 2006. 


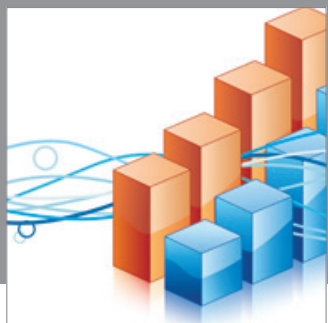

Advances in

Operations Research

mansans

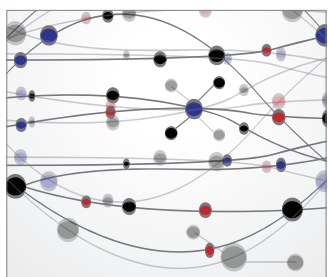

The Scientific World Journal
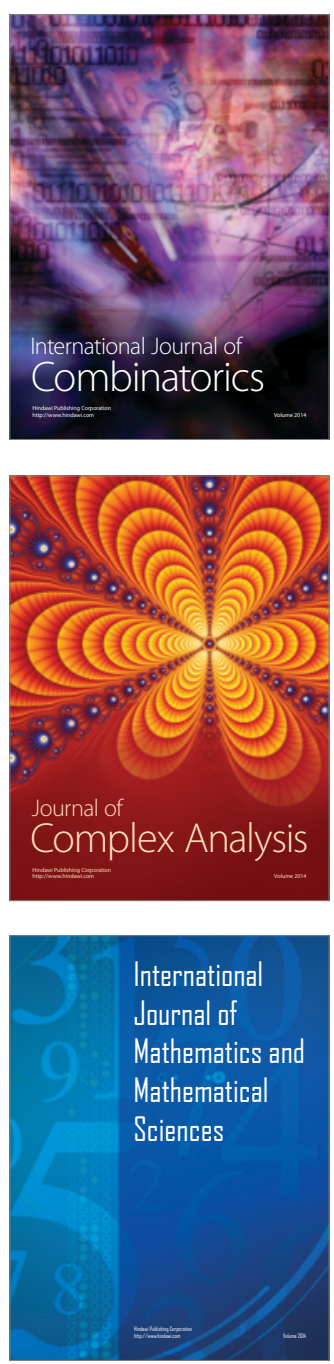
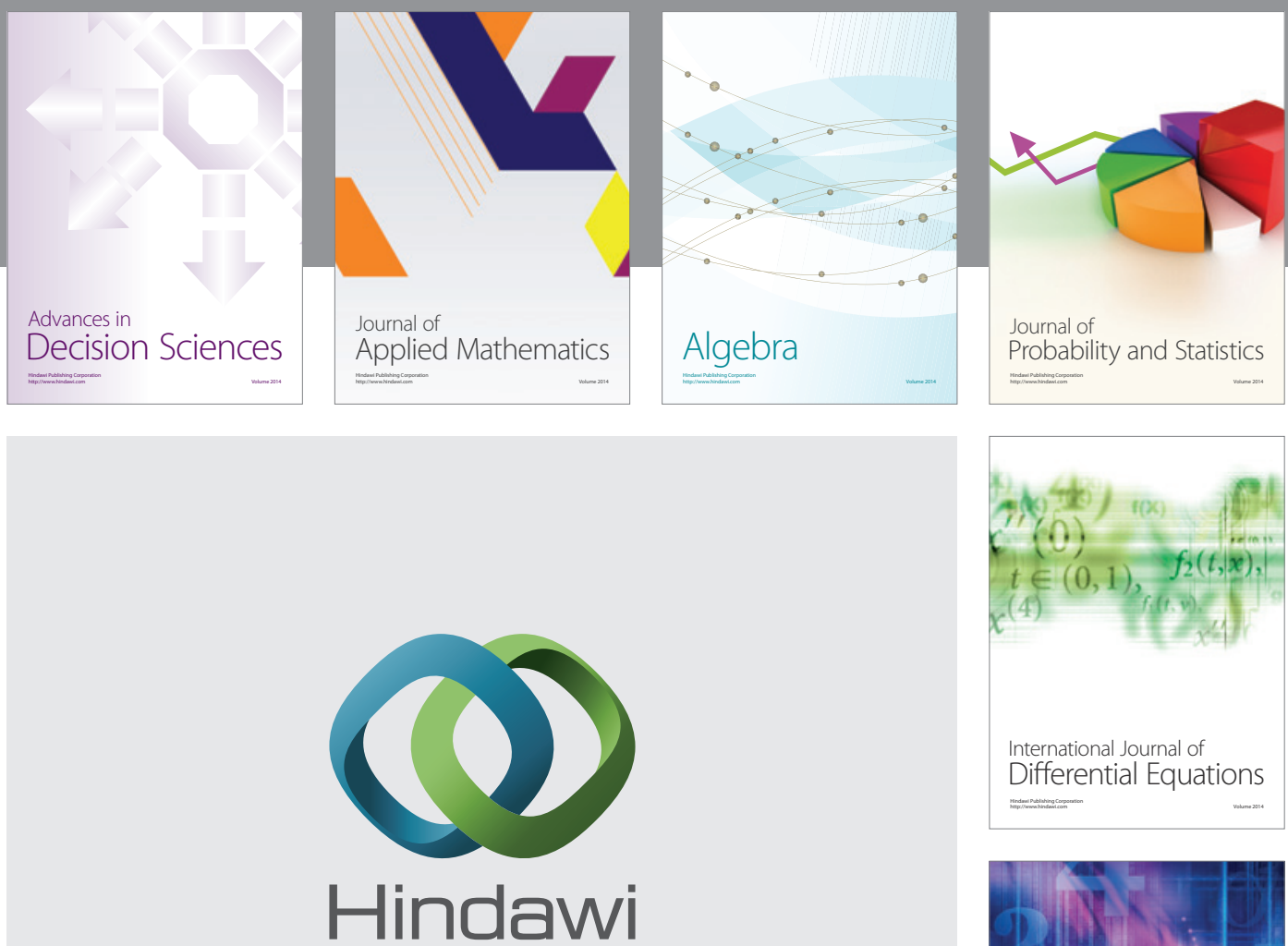

Submit your manuscripts at http://www.hindawi.com
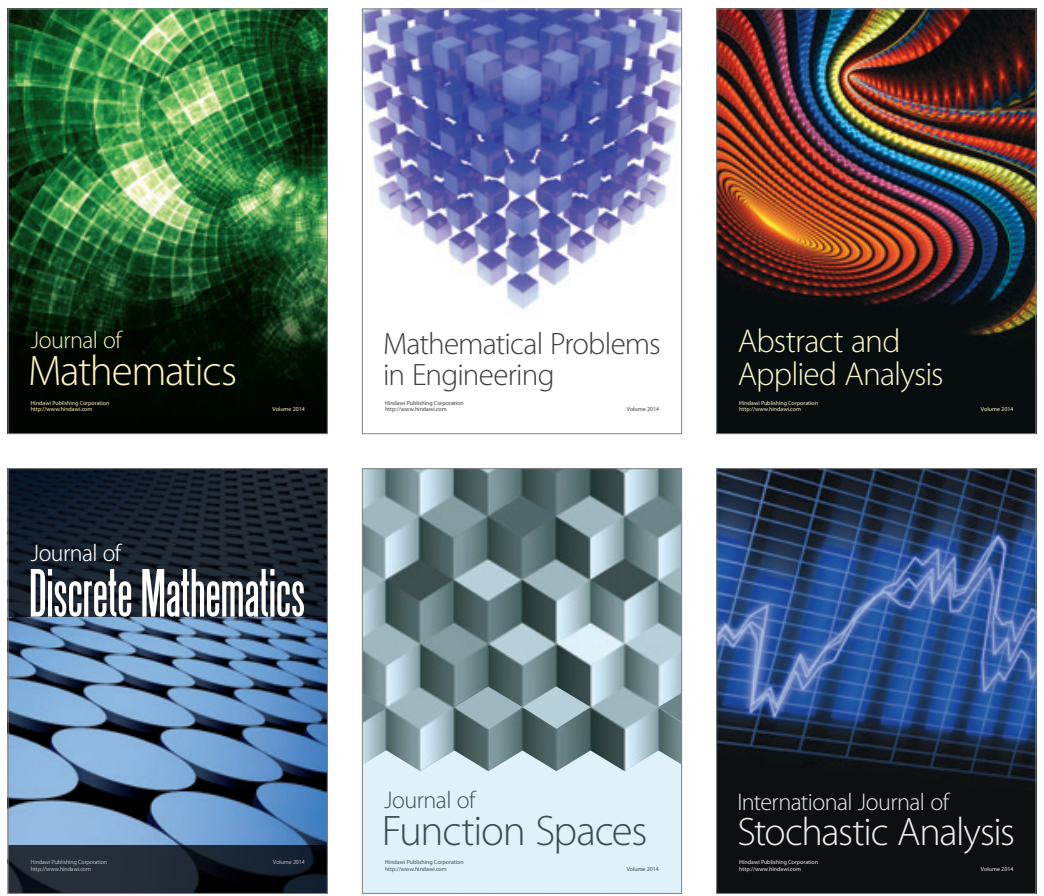

Journal of

Function Spaces

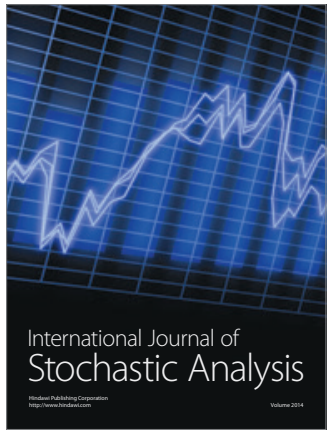

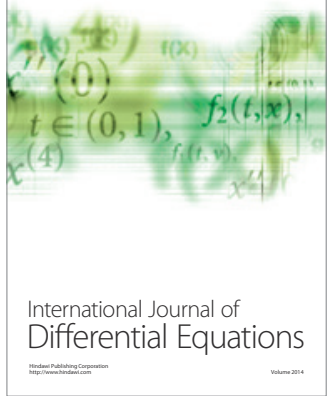
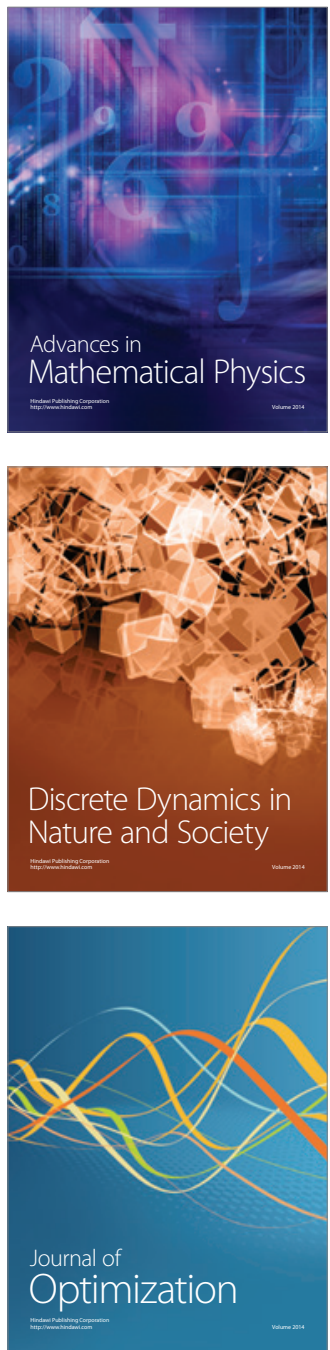